VATT Working Papers 124

\title{
Job Tasks and Gender Wage Gaps within Occupations
}

Aspasia Bizopoulou 


\title{
VATT WORKING PAPERS
}

\section{4 \\ Job Tasks and Gender Wage Gaps within Occupations}

\author{
Aspasia Bizopoulou
}


Aspasia Bizopoulou, VATT Institute for Economic Research, Arkadiankatu 7, PL 1279, 00101 Helsinki, Finland. Email: a.bizopoulou@gmail.com or aspasia.bizopoulou@vatt.fi

I am grateful to Maia Güell, Wolter Hassink, Mathijs Janssen, Kristiina Huttunen, Tuomas Pekkarinen, Janneke Plantenga, Anna Salomons, Lucas van den Velde, as well as participants from the Morning Coffee VATT Seminar 2019, the 2016 GRAPE conference in Warsaw, the 2016 RES Annual Conference in Bristol and from graduate seminars at Edinburgh and Utrecht. I would also like to thank Kathrin Hoeckel and William Thorn, who first brought to my attention the existence of PIAAC. An earlier version of this paper circulated as 'Task Profiles and Gender Wage-gaps within Occupations'.

ISBN 978-952-274-243-8 (PDF)

ISSN 1798-0291 (PDF)

Valtion taloudellinen tutkimuskeskus

VATT Institute for Economic Research

Arkadiankatu 7, 00100 Helsinki, Finland

Helsinki, October 2019 


\title{
Job Tasks and Gender Wage Gaps within Occupations
}

\author{
VATT Institute for Economic Research \\ VATT Working Papers 124/2019
}

Aspasia Bizopoulou

\begin{abstract}
I provide evidence that task use at work by men and women in the same occupations is significantly different. The observed difference can account for the within-occupational gender-wage gap that is prevalent in many developed countries. Using data for thirteen European countries, I find that women consistently report spending less time than men on specific job tasks. The effect is exacerbated with fertility and selection into the labour force, however neither mechanism can completely account for the observed differences. The difference is also not accounted for by the type of occupations in which women are employed, nor their working hours and it is not driven by measurement error. Similarly to studies for the US and Australia, I find that a large portion of the gender wage-gap is found among individuals employed in the same occupational titles. However, controlling for both occupations and task use in an wage equation accounts for the entirety of the within-occupational gender wage-gap, for all countries in the sample.
\end{abstract}

Key words: task approach, gender wage-gap, occupations

JEL classes: J16, J24, J31 


\section{Introduction}

A number of studies have highlighted the existence of a gender wage-gap among men and women working in identical occupations (Goldin (2014); Cobb-Clark and Tan (2011); Korkeamäki and Kyyrä (2006)). Occupations are used in the literature with the assumption that individuals classified in the same occupation have comparable specialised human capital. Thus, the existence of a gender wage-gap within occupations, on top of the well-established gap between different occupations, is a puzzle. It cannot be rationalised within the framework of occupational segregation or differential human capital, since we are looking at individuals with identical occupational titles, reflecting not only the type of skills used but also the level. ${ }^{1,2}$ Thus, the objective of this paper is to study the drivers of the gap in wages among men and women working in the same occupations.

Despite holding identical occupational titles, there exists evidence that the day-to-day content of the male and female version of a job might be different, and in turn have an impact on the wage-gap. Goldin (2014) shows that a substantial proportion of the gender gap in the US among individuals employed in identical codes can be attributed to a premium for working long and inflexible hours in certain specialisations such as law and consulting. Indeed, using representative data from lawyers in the US, Azmat and Ferrer (2017) show that women both bill significantly fewer hours and bring in less client revenue than men, this being partly due to the presence of children. Moving away from the law profession, Babcock et al. (2017) use data from academics of a large institution in the US to show that women are both more likely to be assigned to and to self-select into low-promotability tasks relative to the men, hampering their career trajectories. Studies from psychology have also highlighted patterns of female-male task differences: women are less likely than men to obtain challenging assignments with high developmental value for careers (McCauley et al. (1994); Benschop and Doorewaard (1998); De Pater et al. (2010)). At the same time, women spend more time than men doing office 'house work', such as organising office parties and social activities or helping new recruits (Kanter (2008); Williams and Dempsey (2018)). Nevertheless, it remains unclear whether differential task distribution is a problem specific to certain industries or it can be generalised across occupations, skill levels and countries; whether fertility is always the primary driver of such differences; and whether there is pass-through of male-female task segregation to the within-occupational gender wage-gap. ${ }^{3}$

In this paper I ask three main questions: i) Do we observe consistent differences in task use among men and women within the same occupations across different countries? ii) What are the drivers behind these differences? iii) Do the task differences play a role in the within-occupational genderwage gap? The first two questions are addressed in the first part of the paper. I document the presence of both raw and conditional task differences among men and women working in the same occupations, across thirteen different countries. I subsequently test whether these differences can be accounted for by any of the usual explanatory factors such as the number of hours worked, fertility shocks, skillbiased female selection into the labour force or a tendency to under-estimate one's performance since task use is self-reported. In the second part of the paper I provide additional evidence on the existence of within-occupational gender wage-gaps in European countries, confirming pre-existing evidence from the US, Australia and Finland. Subsequently, I test whether these within-occupational gender wage-

\footnotetext{
${ }^{1}$ For example, Polachek (1981); Sorensen (1989); Groshen (1991); Blau and Kahn (2000); Goldin (2006) provide an overview of the role of occupational choice for women's wages.

${ }^{2}$ The ISCO 2008 occupational classification is correlated with the required skill level in descending order: occupations starting with code 1 require higher skills than those starting with code 9

${ }^{3}$ A recent working paper by Petö and Reizer (2019) is addressing a similar question.
} 
gaps can be explained by the differential level of male and female task use in traditional reduced form Mincer equations.

Central to this analysis is the use of the 'Programme for the International Assessment of Adult Compentencies', a dataset compiled by the OECD. Its key feature is the extensive information on the use of different tasks at the individual-level, allowing us to document differences by gender and within occupational categories. Furthermore, the task use information can be combined with individual hourly wages and can be easily compared across thirteen European countries.

I find that differences in task use among men and women in the same occupations are significant for all countries in the study. More specifically, women are documented to be less intensively involved than men in all task dimensions, i.e. they perform the same tasks less often than men. Tasks types are grouped into seven categories: social; management; literacy; numeracy; ICT; problem solving and manual tasks. With the exception of manual tasks, women report usage at lower intensity than the men even when controlling for occupational fixed effects. The average gap is 0.15 , which corresponds to a fifth of a point on the scale of 1 to 5 for task use intensity. In the category of manual task usage we document opposite trends for occupational versus task segregation: women are more likely to be in occupations with higher levels of manual tasks relative to the men, but within occupations women's use of manual tasks is much less intensive to the men's. These stylised facts are in contrast to the results by Autor and Handel (2013) for the US, who find that there aren't significant differences in task use among men and women, once occupational fixed effects are controlled for.

The differences in task usage within occupations persist across a set of common explanatory factors, with the exception of manual tasks. Hours worked hardly change women's baseline lower task usage for most task types. A fertility shock, measured by comparing women with one, two, three, or four children to women without children greatly exacerbates the gap in task use, but does not entirely account for the baseline difference, with the exception of Management tasks in Northern and Southern Europe. Nevertheless, Problem Solving, Literacy, Numeracy and ICT continue to exhibit large baseline gaps even after acknowledging the presence of children. The different countries in the sample having vastly different female participation rates, the next possible explanation is that of female selection into the labour force and its impact on task use gaps. Lower participation rates tend to be associated with higher positive selection among women which can in turn explain lower male-female gaps, as in Olivetti and Petrongolo (2008). I find that Literacy, Numeracy and ICT task usage is weakly correlated with female labour force participation: countries with higher female activity rates like the Netherlands, Denmark and Norway have higher negative gaps in task use. Nevertheless, the only statistically significant correlation is for Numeracy. Finally, since the extent of task use is self-reported, I study the possibility of under-reporting among women. The psychology literature has highlighted that women tend to under-estimate their own performance in situations involving some element of competition. We compare the task use among women working in the private versus the public sector, the assumption being that the private sector will involve higher levels of competition than the public sector. I find that Problem Solving is the task category most prone to measurement error since the male-female gap almost disappears once we compare the gap in the public-private samples. The category 'Problem Solving' has the most vague description among all the different task categories, so it is reasonable to assume that it is mis-interpreted by men and women, given the existing literature of self-evaluation.

I then study the explanatory role of task segregation on the gender wage-gap. Extending the results from studies by Goldin (2014) and Cobb-Clark and Tan (2011), I document a substantial gender wage- 
gap within occupations in all thirteen countries of the sample. Subsequently I control for task use intensity by gender in a reduced-form wage equation and show that there is no remaining unexplained gender-gap within occupations. In Northern Europe, the gap becomes positive and weakly significant, suggesting that once both occupational and task fixed effects are taken into account, women have slightly higher wages than men in the same occupation. In Eastern and Southern Europe, the gender wage-gap is reduced to zero once we control for both occupational and task fixed effects.

The caveat of the above results is that they are based on relatively small samples per country and are descriptive in nature. However, the gaps in job activities have been precisely measured for only two professions (lawyers and academics) and only in the US. ${ }^{4}$ Our results highlight that male-female gaps in job tasks are present across the spectrum of occupations and across different countries. Furthermore, the inclusion of task use in a wage equation leads to the disappearance of the an otherwise puzzling gender wage-gap among individuals in identical occupations, for all countries present in the analysis.

The rest of the paper is organised as follows: section 2 presents the data; section 3 documents the differences in task use for men and women and outlines explanatory factors; section 4 presents the results on task use and gender wage-gaps. Section 5 concludes.

\section{Data}

I use the 1st round of the Programme for the International Assessment of Adult Competencies (PIAAC) for the year 2011, produced by the Organisation for Economic Cooperation and Development (OECD). The 13 countries used in this study are: Belgium (Flanders), The Czech Republic, Denmark, France, Greece, Italy, The Netherlands, Poland, Slovakia, Slovenia, Spain, the UK and Norway. ${ }^{5}$ Table 1 gives an overview of the sample, excluding the self-employed. As has been observed in previous studies with different data, in the PIAAC data the female hourly wage is lower than the male; the average number of hours worked is lower for women than for men; the activity rates are lower for women; and the average years of education are higher for women. ${ }^{6}$ These stylised facts hold for all countries available in the sample.

Table A.1 provides an overview of the 40 general tasks that characterise occupations. Each task can be performed at five different levels of intensity, as reported by the individual: (1) never, (2) less than once a month, (3) less than once a week but at least once a month, (4) at least once a week but not every day and (5) every day. The available task categories are the same for all occupations and across the thirteen countries, allowing for the comparison of task usage and return by occupation. ${ }^{7}$ It is worth noting that cognitive tasks are much better measured than manual tasks in the current dataset - only 2 out of the 40 tasks concern manual activities. The lack of precise measurement of manual tasks provides a level of measurement error, since high-skilled and low-skilled manual work is not distinguishable a priori. Thus, the contribution of manual tasks on outcomes like wages are likely to be more strongly correlated with education, relative to the rest of the task categories. This

\footnotetext{
${ }^{4}$ See the studies by Azmat and Ferrer (2017) and Babcock et al. (2017).

${ }^{5}$ The survey has been run in a total of 41 OECD countries. Countries not present in this analysis have incomplete data on either earnings or occupational information or both, which are required for this study.

${ }^{6}$ See for example Gicheva (2013) and Goldin (2014) for differences in hours worked; Olivetti and Petrongolo (2008) for gender differences in participation rates; Pekkarinen (2012) for gender differences in educational attainment.

${ }^{7}$ Other datasets containing task information are the O*NET and Princeton Data Improvement Initiative (PDII) for the US, and the BIBB for Germany. The task information in the O*NET is provided at the occupational level only, while the PDII uses individual-level task information at very high levels of aggregation (10 tasks to cover all occupations). The BIBB for Germany is the most closely comparable dataset to PIAAC.
} 
happens to be the case and is discussed further in section 3 and 4. Moreover, since the survey does not provide us with the difficulty level of each task, we rely on achieved education to control for the individual's potential skill level.

\section{Male and Female Task profiles}

\subsection{Baseline Differences}

Figure 1 shows the overall differences in task use by gender across the entire sample and across all 40 tasks. ${ }^{8}$ Overall, women are using tasks at lower levels of intensity than men. In Figures 2-8, having grouped tasks into 7 broader categories (social, management, problem solving, literacy, numeracy, ICT, manual), I present the average levels of task use by gender and by country cluster. On average, men's task use tends to be slightly higher than women's, especially at higher levels of intensity. The starkest differences between men and women are in Problem Solving, Literacy, Numeracy, and ICT, where the two distributions clearly cross and the male distribution is to the right of the female for Northern and Southern Europe, and slightly less so for Eastern Europe. For the rest of the task categories, the male-female difference appears primarily at the highest levels of intensity only, where men consistently report using certain type of skills everyday more often than women. The differences in task intensity are generally more pronounced in Northern Europe.

The rest of section 3 is devoted to understanding the origin of the gaps in task use between men and women. The primary aim is to disentangle whether the observed gaps are a robust statistic permeating different educational backgrounds and work circumstances, or whether they can be accounted for by well-known male-female labour market differences such as occupational segregation; fewer hours worked among women; fertility shocks having an unequal impact on the work trajectory of men and women; lower employment rates among women and ensuing skill selection; or measurement error in the task use variables due to women under-reporting their performance.

\subsection{The role of occupations and hours worked}

I first study the extent to which differential task usage by gender can be explained by individuals' human capital, demographic characteristics and job attributes. We are particularly interested in whether women are more or less active in different types of tasks relative to the men, and whether these differences are a result of job-related characteristics. Following Autor and Handel (2013) the baseline OLS regression is the following:

$$
T_{i j}=\beta_{0}+\beta_{1} \text { female }_{i}+\delta_{1} S_{i}+\zeta_{j}+e_{i j}
$$

where vector $T_{i j}$ is a discrete variable ranging from 1 to 5 measuring task intensity in the task category of interest. The number of discrete values that the variable can take varies from one task category to another - for the manual category there are only 8 possible values, while in literacy there are 48 . The difference in these numbers reflects how many different tasks are under one category: a higher number of tasks will result in a higher number of discrete values. The vector $S_{i}$ includes individual human capital as measured by schooling; experience and whether one took the survey in one's native

\footnotetext{
${ }^{8}$ In the graph, the 5 different intensity levels of task use have been condensed into a 0/1 dummy, where 0 includes 'never' and 'less than once a month' and 1 includes 'less than once a week but at least once a month'; 'at least once week but not everyday' and 'everyday'.
} 


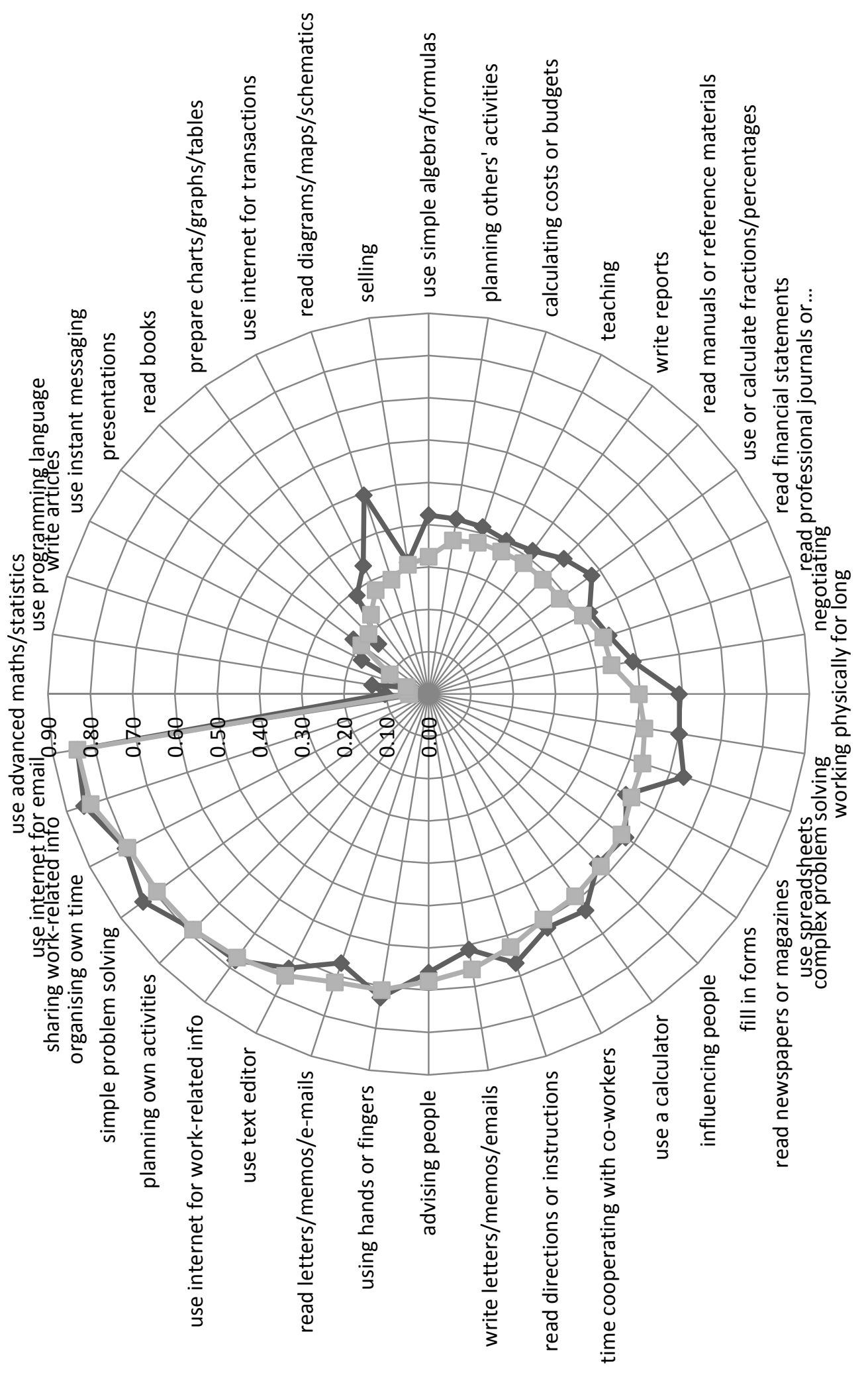


language. Since we do not have information on race or ethnicity, our only demographic characteristic of interest is gender. $\zeta_{j}$ is a vector of 260 dummies for the individuals' occupation at the 4-digit level, controlling for occupational segregation. Occupational segregation by gender has been documented in most developed countries, and it is reasonable to assume that part of the differences in task use will be a result of occupational segregation.

Results for the baseline regression can be seen in Tables A.3-A.5 in the Appendix, where we provide separate tables for Northern, Southern and Eastern Europe. In odd-numbered columns, which exclude occupational fixed effects, women report spending less time than men in most type of tasks, in all regional clusters. We do not see any male-female specialisation in tasks, i.e. we do not see women using one type of task and men another. The main statistic is that women's task use intensity is lower in all available tasks relative to men's, with the exception of manual tasks. There are some regional differences in the magnitude of the gap: generally, we see larger male-female differences in Northern Europe across occupations.

Adding occupational fixed effects (in even columns) does not significantly decrease the gap for the most part. In Eastern Europe (Table A.5) the task use gap even increases, appearing to be larger within rather than between occupations. Thus, the observed differences in task use intensity are not the result of occupational segregation, but are as much present across different occupations as they are within the same occupational titles. The exception comes for manual tasks, where we observe much larger and statistically significant variations once controlling for occupational fixed effects. Manual tasks are rather crudely measured in PIAAC, rendering the category much less informative in terms of the skill-level of the manual task. For example, a factory worker with unskilled tasks will appear to do the same tasks as a ceramist or a jeweler, both of which require many years of training. Thus, it is not so surprising that controlling for occupational fixed effects brings about such dramatic changes, not just on the female coefficient but also on the education and experience effects. ${ }^{9}$ Adding the occupational fixed effects also significantly increases the R-squared from an average 0.15 up to an average 0.4, values which are close to the those in Autor and Handel (2013), who obtain an R-squared of 0.55 while using task content data from the O*NET. However, unlike in Autor and Handel (2013), we see that controlling for occupational categories does not attenuate the statistical significance of the female dummy. Across different countries there appear to be systematic sex differences in task use among workers within the most granular definition of occupations.

Table 2 extends the results of equation 1, by controlling for number of hours worked. As is shown in the summary statistics of Table 1, women tend to work fewer hours than men in all countries. Fewer numbers of hours worked have been linked to lower hourly wages in Goldin (2014), especially for occupations providing little worktime flexibility. In the context of task use, it is reasonable to assume that working fewer hours may lead to different task portfolios for men and women, in particular lead women appearing to have artificially lower levels of task use. Table 2 splits the results by region: panel A shows results for Northern Europe; panel B for Southern and panel C for Eastern. Each column

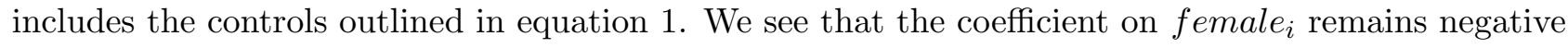
when controlling for hours for most types of tasks. The only exception is with Manual tasks in column (7), where the gap is reversed, again reflecting the imprecision of the manual task category. The effect

\footnotetext{
${ }^{9}$ The education goes from the negative to positive once the occupational fixed effects are added. Thus, high intensity manual tasks are more common for those with less education. Once controlling for occupations - and, indirectly, for the skill-level of the occupation - the intensity of manual tasks now becomes higher for those with higher levels of education. The same pattern is true for experience.
} 
of working additional hours on task use is positive, but relatively small.

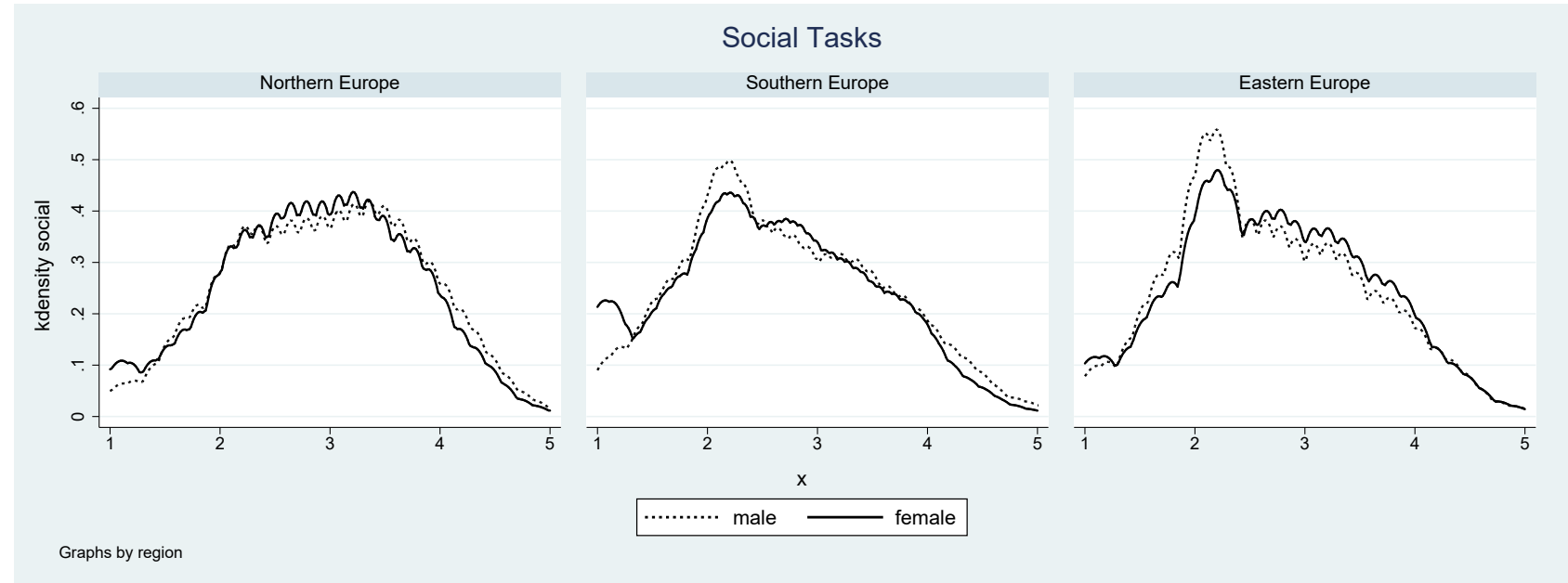

Figure 2: Social Tasks

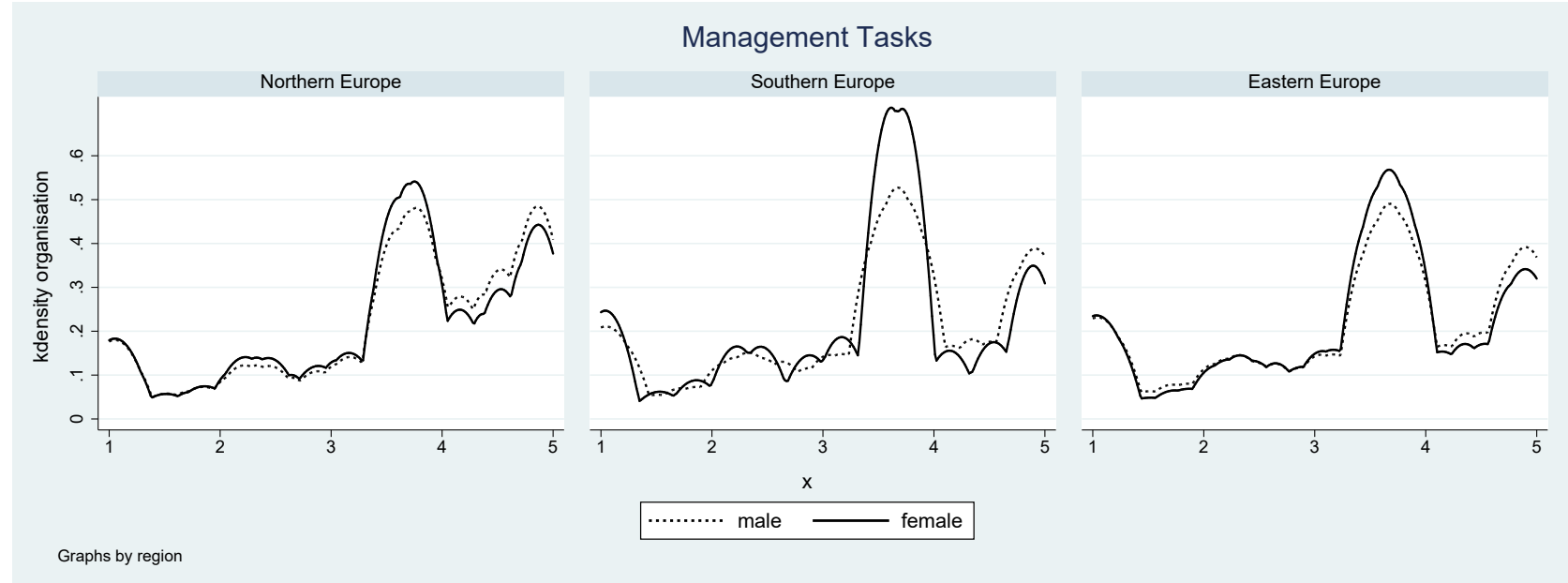

Figure 3: Management Tasks

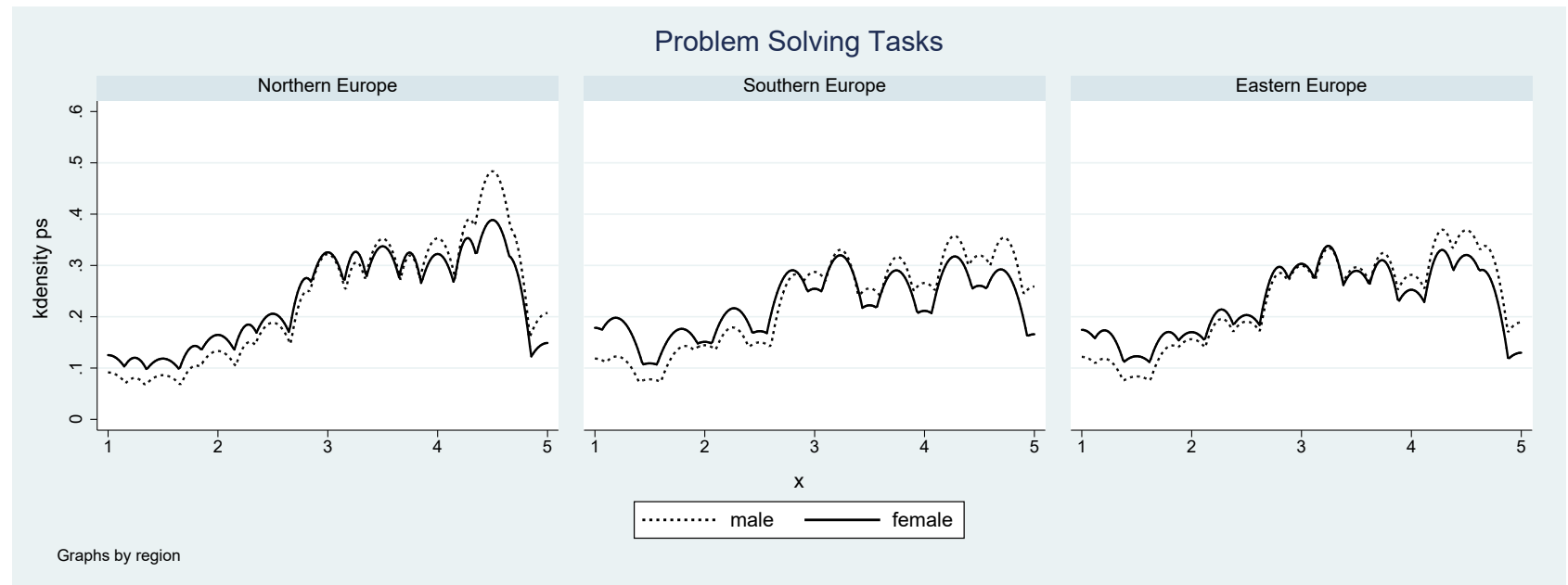

Figure 4: Problem Solving Tasks 


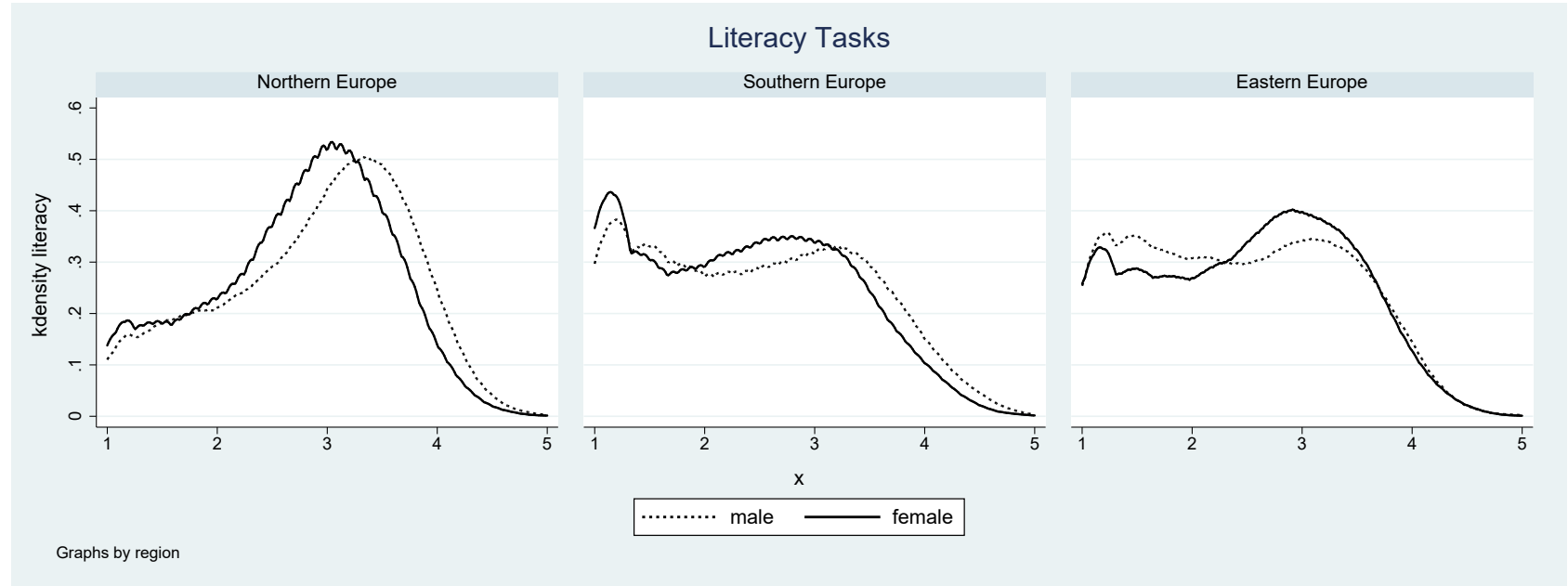

Figure 5: Literacy Tasks

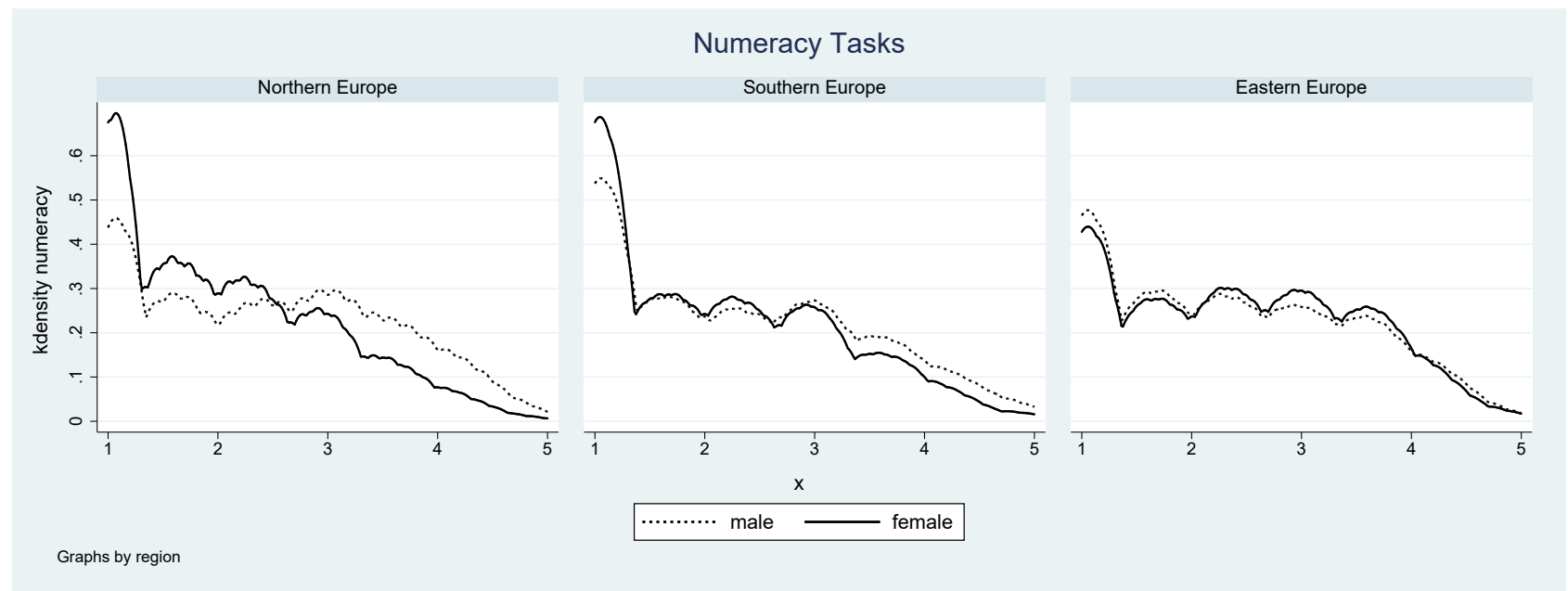

Figure 6: Numeracy Tasks

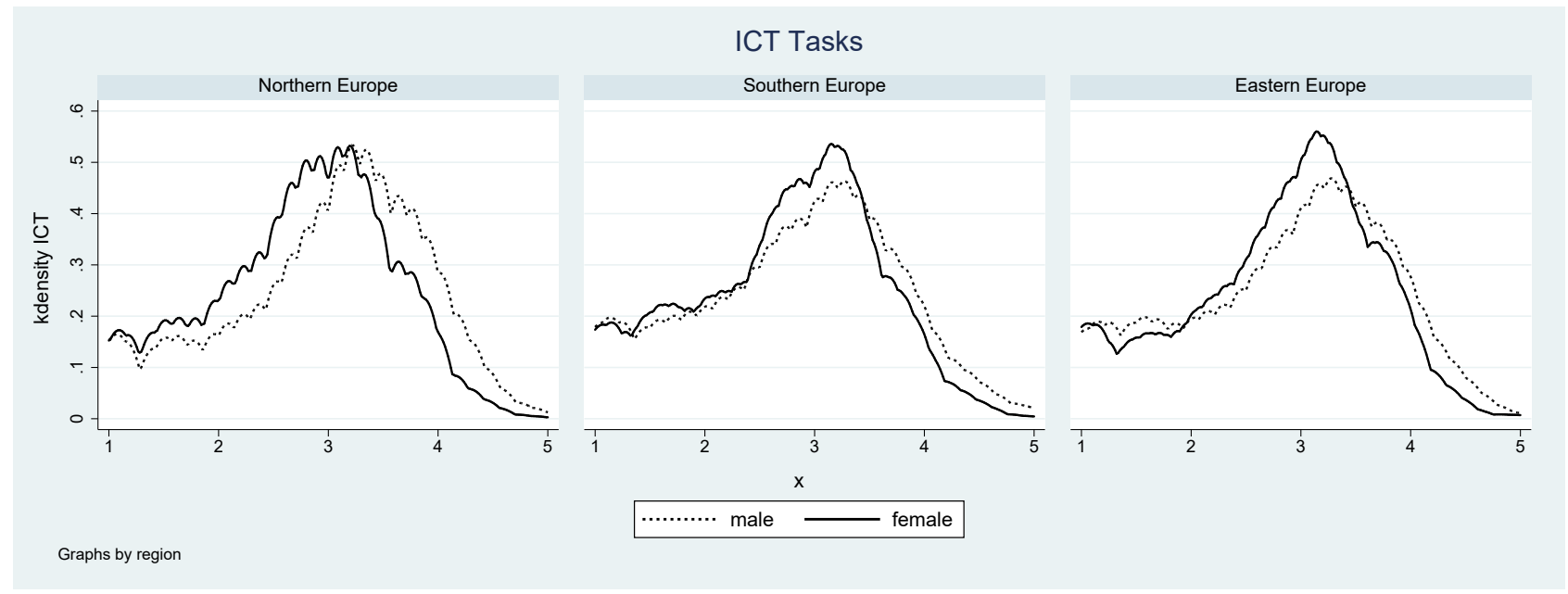

Figure 7: ICT Tasks

\subsection{The role of fertility}

Since neither occupational fixed effects, nor hours worked can adequately account for the difference in task use at work between men and women, we next turn to study the effect of fertility. Several studies have shown that earnings trajectories of men and women tend to diverge after giving birth, 


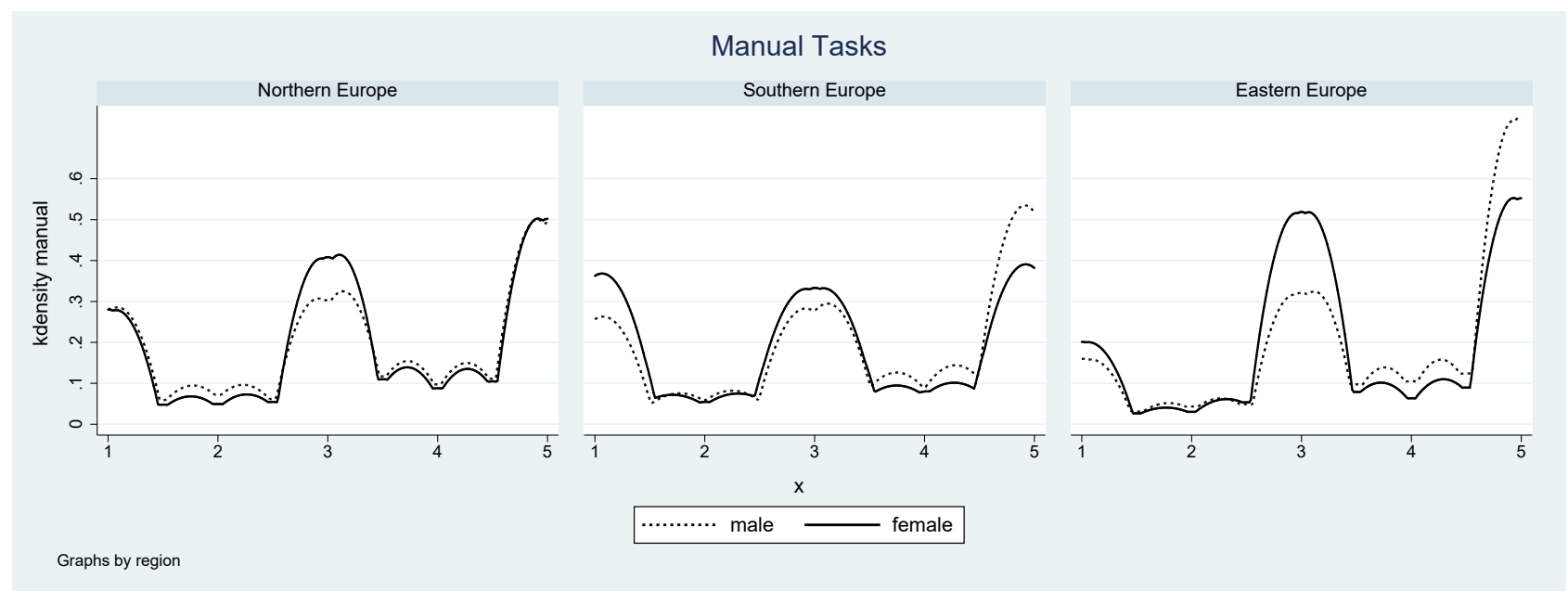

Figure 8: Manual Tasks

with women taking a substantial hit straight after maternity, which continues for the rest of their working lives (Bertrand et al. (2010); Angelov et al. (2016); Kleven et al. (2018)). Coupled with a decrease in earnings, fertility may also lead to a substantial re-organisation of women's work tasks, which is what we test for in this section. We estimate the following equation for each of the three regions of the sample:

$$
T_{i j}=\beta_{0}+\sum_{k=1}^{4} \beta_{k} \text { Child }_{i k}+\sum_{k=1}^{4} \gamma_{k} \text { female }_{i} * \text { Child }_{i k}+\delta_{1} S_{i}+\delta_{2} \boldsymbol{X}_{i}+\zeta_{j}+e_{i j},
$$

where $T_{i j}$ is defined as in section 3.2. Here, we also include a set of four dummies for whether the individual has $1,2,3$ or $\geq 4$ children (the reference category is 'no children') and then add a set of multiplicative dummies for having children and being female. The vector $S$ includes human capital controls (education, experience, whether individual is native speaker); $\boldsymbol{X}$ includes demographic characteristics (gender, age); $\zeta$ is a vector of occupational dummies.

The results are presented in Tables 3-5. Women continue to have lower levels of baseline task use than men in most dimensions, even after controlling for fertility shocks. The baseline coefficient on female fluctuates between -0.09 and -0.24 across regions, i.e. between a tenth and a quarter of a point in the 1-5 scale of task-use intensity. Fertility appears to particularly exacerbate the differences in task use in Northern and Southern Europe, with the size of the coefficient significantly surpassing the baseline effect once there are two or more children. The tasks most sensitive to fertility effects in these regions are social and management tasks, which are both contact-intensive and mirror the reduced contact hours that women can offer after children. Once the high levels of caring are controlled for, however, there are appears to be no significant baseline gap in social and management tasks between men and women. Nevertheless, fertility doesn't appear to be an important factor in the unequal distribution of tasks in Eastern Europe, as well as for the unequal distribution of tasks like Literacy, Numeracy, ICT and Problem Solving in all of the countries of the study. Overall, Tables 3-5 show that fertility in combination with occupational choice certainly exacerbate the gap in contact-intensive tasks but are not sufficient to explain the consistently lower task use among women along most task dimensions.

As an additional robustness check, I test for differences in task use by age. The intention is to control whether there is significantly lower usage of tasks among women of the age group that is prone 
to starting a family. The results for each regional cluster can be seen in Tables 6-8. For both men and women and for all tasks in all regions, there is a marked decrease in the task-use intensity as workers get older. However, there are no significant differences in the task use of women of child-bearing age relative to women in different stages of life, as can be seen by the very small and statistically insignificant coefficients on the multiplicative terms between the age category and female dummy. These results provide additional evidence that the observed differences in task use by gender are not primarily driven by women of child-bearing age undertaking fewer tasks at work.

\subsection{The role of female labour force participation}

A separate but equally relevant mechanism for the observed gaps in task use by men and women is the role of labour force participation. Olivetti and Petrongolo (2008) have highlighted the role of the different participation rates across countries to rationalise the substantial differences in the pay gaps from one country to the next, and Mulligan and Rubinstein (2008) have shown the importance of selection into the labour force to explain the closing of the gap over time. In the context of a gender gap in task use, the main question of interest is whether different participation rates across countries can partly explain the difference in the size of task-use gaps, by means of either positive or negative selection of women into the labour force. The underlying assumption is that a female labour force with higher average skills than the male labour force will be less likely to have a different task profile to men working in the same occupations. Figures 9-15 plot the rates of female labour participation in each country and the magnitude of the gender-gaps in task-use. Task-gaps in analytical skills like numeracy, literacy, problem solving and ICT are negatively correlated with the female rate of participation, although the only statistically significant correlation is that of the gap in numeracy tasks. Gaps in social and manual tasks are hardly correlated with the female participation rate.

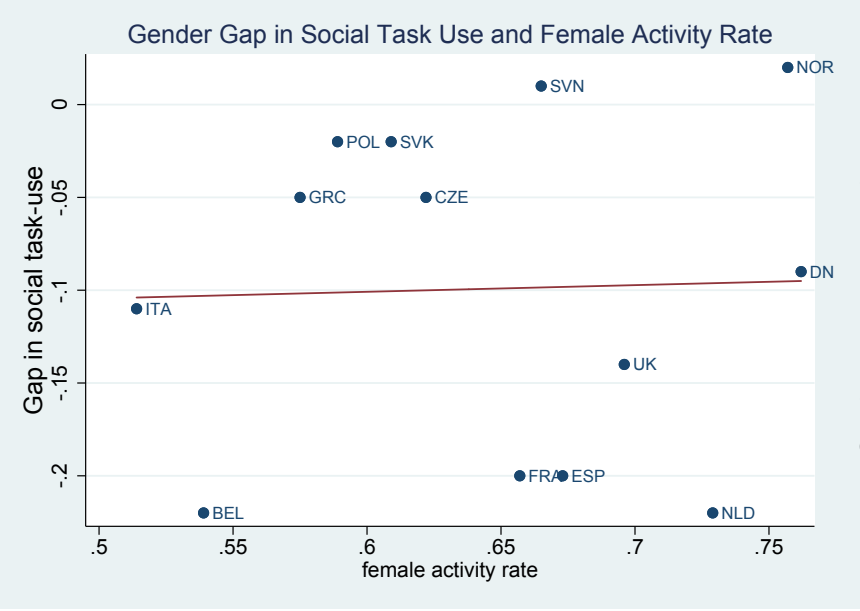

Figure 9: Social Task Gap

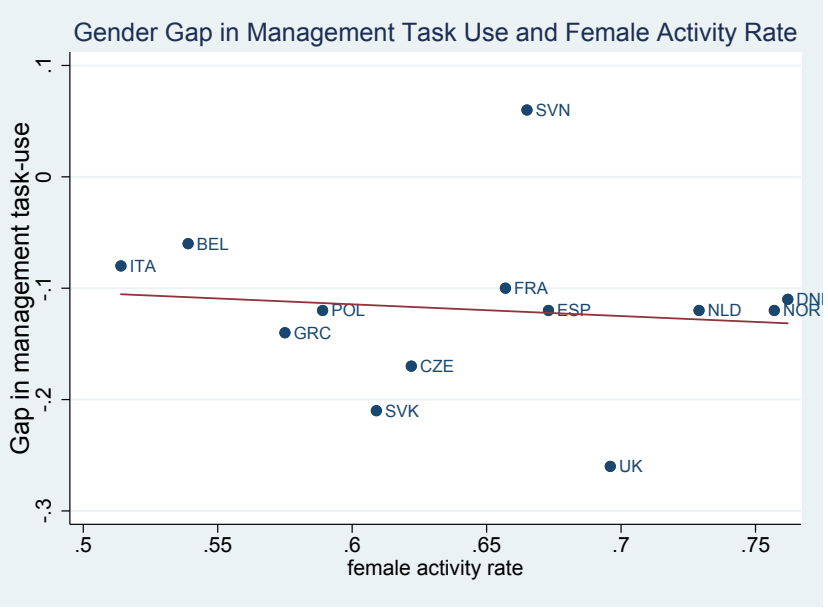

Figure 10: Management Task Gap 


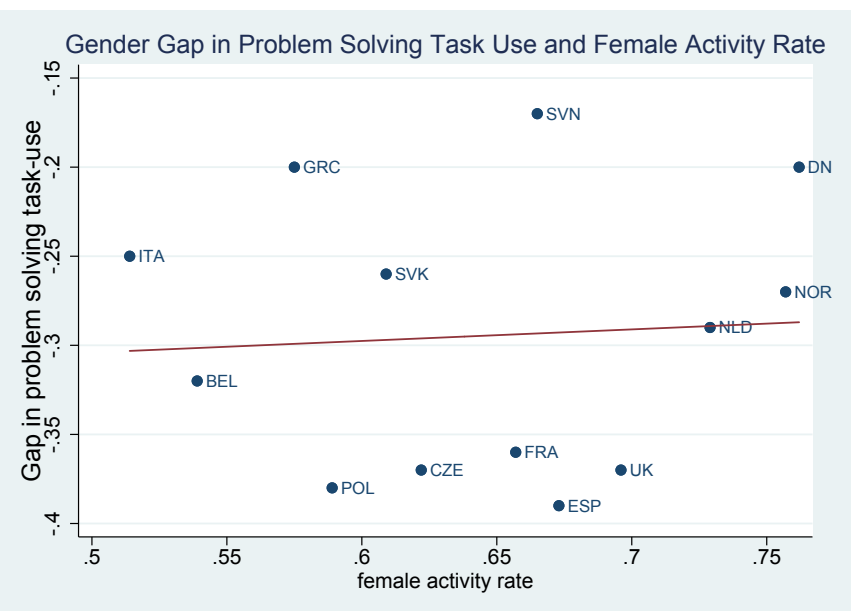

Figure 11: Problem Solving Task gap

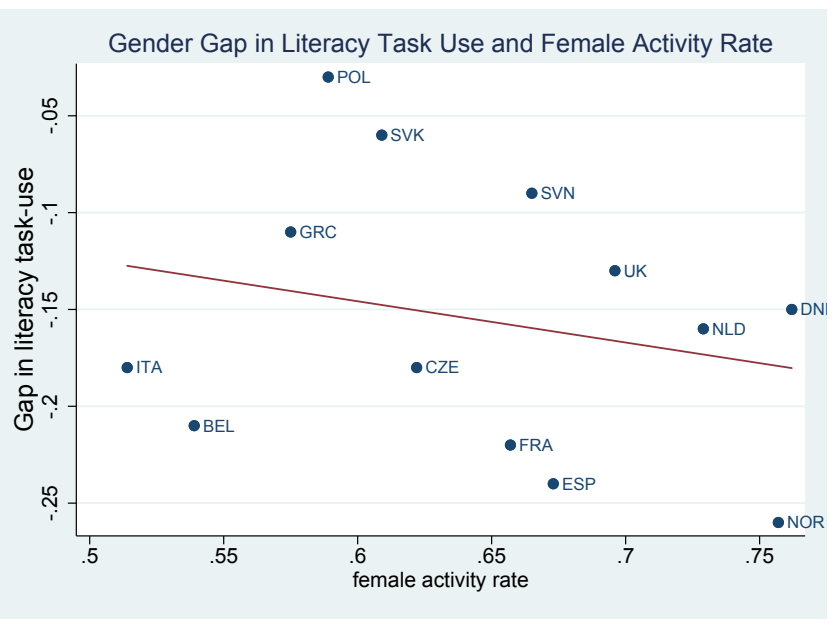

Figure 12: Literacy Task Gap

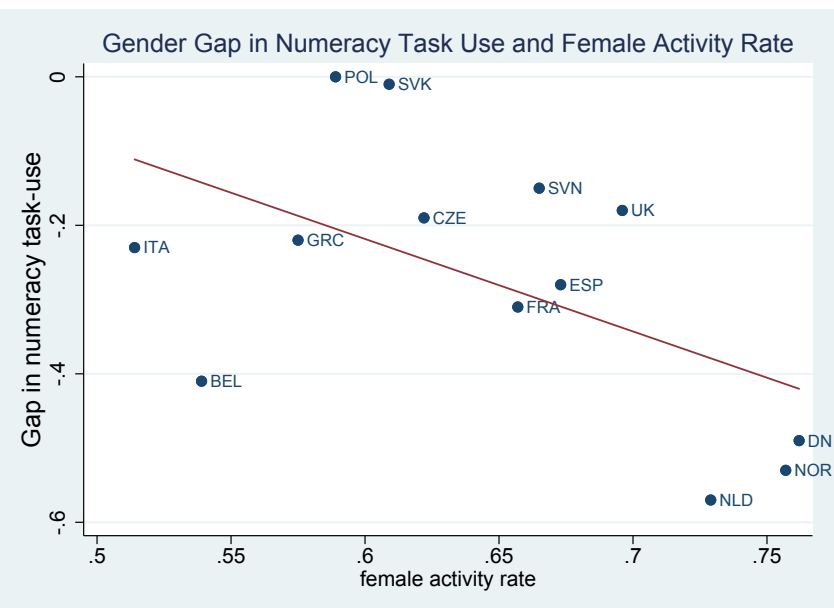

Figure 13: Numeracy Task Gap

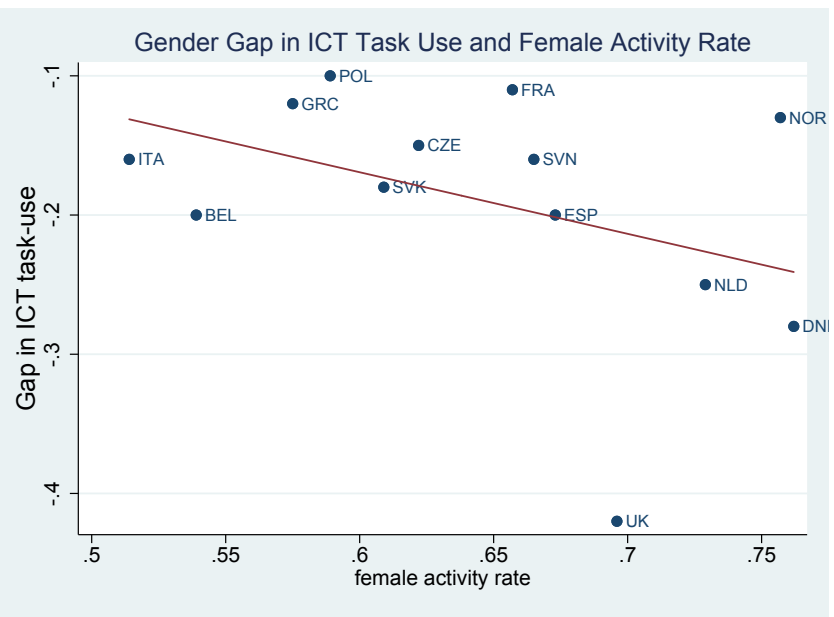

Figure 14: ICT Task Gap

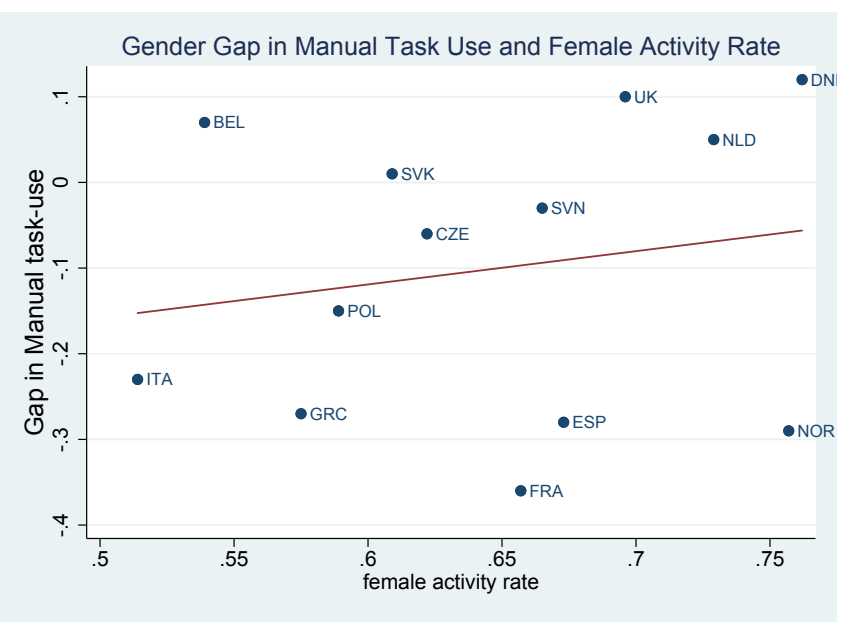

Figure 15: Manual Tasks Gap

The negative and significant correlation between the participation rate and numeracy suggests positive selection into the labour force on numeracy use at work. The negative correlation is starkest between Northern and Southern Europe in particular: in the former, there are high participation rates combined with high gaps in task use, while in the latter low participation rates appear with much 
lower gaps in task use. Selection into the labour force is a driving factor for the observed differences in numeracy gaps, but the evidence is much weaker regarding the rest of the types of tasks. Thus, we can conclude that labour force participation is not the main driver for most of the observed gaps in task use.

\subsection{The role of psychology}

Finally, a possible mechanism for the consistently lower task use observed among women relative to men is measurement error, in the form of women under-reporting their true involvement with various work tasks. Studies from the psychology literature have shown that women tend to under-estimate their own performance in competitive environments such as test-taking both in the field or in the lab (e.g. Beyer (1990); Beyer and Bowden (1997); Bengtsson et al. (2005)). At the same time, men tend to over-estimate their performance, but may also tend to be truthfully over-active in certain competitive settings. For example, in Barber and Odean (2001), it is shown that men tend to trade $45 \%$ more than women, even when trading reduces net returns relative to women's. Although most workplace conditions are far from the type of competitive environments created during a lab experiment, an exam or a trading floor, the observed gap in reported task use may be driven by women under-estimating or men over-estimating their performance as a result of competition at work. In other words, we are presented with the possibility of measurement error in task use. While we do not have direct measures of the level of competition at work, we can compare certain workplaces which we expect to have differences in their level of competition. At the risk of over-simplification, we split workplaces by whether they are public or private, the assumption being that performance in private workplaces will be more closely monitored than in public workplaces and employees will more likely perceive them as being more competitive.

We estimate a modified equation 1, where we add a multiplicative control variable for whether women work in the private or the public sector. Results are in Table 9. Assuming that the publicprivate distinction works through the channel of levels of competition, we observe that the negative coefficient on female is reduced, particularly in Northern Europe. In Southern and Eastern Europe the distinction between working in a private and public workplace has less effect on the male and female tasks, with the exception of problem solving. Nevertheless, the baseline negative coefficient on female is never completely dominated by working in the public sector since $\mid$ female $_{i}|>|$ female*public $\mid$. Thus, the difference in task use between men and women cannot be entirely explained by differing levels of competition and possible under-reporting.

\section{Task Use and the Gender Wage-Gap}

In the previous section, we established the existence of persistent gaps in task use among men and women that are not entirely explained by occupations, hours worked, fertility shocks, skill selection, or under-reporting. In this section, we turn to the study of whether less intensive task use could account for part of the gender wage-gap among individuals working in the same occupation. The basic economic intuition is that the more differences between men's and women's tasks within an occupation, the lower the substitutability of the two and the more likely the existence of a gender wage-gap. 


\subsection{Accounting for the female wage gap: the role of occupations}

In studying the role of tasks as an explanatory factor of the gender wage-gap, we first have to rule out the effect of occupational segregation, since it is usually a predictor of wage-gaps. Clusters of tasks are occupation-specific and accounting for occupational segregation will ensure that we are capturing the effect of task differences over and above occupational differences, when accounting for the gender wage-gap. Following the estimation procedure of Goldin (2014), we add occupational fixed effects in an hourly wage equation. We estimate the following:

$$
\ln w_{i j}=\beta_{0}+\beta_{1} \text { female }_{i}+\delta_{1} \boldsymbol{X}_{\boldsymbol{i}}+e_{i j},
$$

Table 10 lists the gender wage gap for the European countries of the sample, grouped into regions. We obtain the coefficient on the female dummy on wages from the most basic wage specification, which includes an age quartic, a dummy for native speakers and dummies for different countries, and gradually add the number of hours worked, the education level and finally, occupational fixed-effects. The exercise allows us to observe the extend to which the coefficient on female weakens and becomes significantly different as we add more controls. Adding occupational fixed effects helps explain up to a third of the gender wage-gap in Northern Europe, up to half in Southern Europe but none at all in

Eastern Europe. These results are similar to Goldin (2014), who finds that adding occupational fixed effects in a wage equation in the US explains at most one third of the gender wage-gap. Thus, in a significant number of developed countries a large proportion of the gender wage-gap is found among individuals in identical occupations and with identical levels of education and hours worked. If we are looking to explain the remaining of the wage-gap we need to understand what is happening within occupations. Job tasks provide an additional level of dis-aggregation on top of occupations.

\subsection{Task-Use Intensity and Gender Wage-Gap}

Taking equation 3 as the baseline, we add controls for task use intensity to study whether any part of the unexplained gender-gap within occupations can be accounted for by differing levels of task-use intensity by gender. We estimate the following equation:

$$
\ln w_{i j}=\beta_{0}+\beta_{1} \text { female }_{i}+\delta_{1} \boldsymbol{T}_{\boldsymbol{i}}+\delta_{2} \text { female }_{i} * \boldsymbol{T}_{\boldsymbol{i}}+\gamma_{j}+u_{i j},
$$

where $\ln w_{i}$ is the log of hourly wages; $\boldsymbol{T}$ is a vector of different task types (social, problem solving, literacy, numeracy, ICT, management and manual); $\gamma$ is a set of occupation dummies. The aim of this equation is two fold: first, we would like to see whether we can obtain a coefficient on female that is not significantly different from zero once controlling for different task intensities by gender and second, whether men and women get paid the same for the same tasks in the same occupation (i.e. whether the coefficient on the multiplicative terms is statistically significantly different from zero). Tables 11-13 show the results. To start with, we show that in all regions there is a basic wage gap after controlling for human capital, experience and demographic characteristics (column 1). Subsequently we add the 7 task dimensions in column (2) and in column (3) we also add occupational fixed effects at the 4-digit level, since individuals' portfolio of tasks will depend on which occupation they are in. We see that in all regions, a higher proportion of manual tasks is more highly associated with a wage penalty, both within and between occupations. We also see that in all three regions, higher levels of literacy, ICT and management tasks are associated with a wage premium. In Northern and Southern Europe (Tables 11, 12), social skills have a significant wage premium. Moreover, we do not find significantly 
different estimates on the coefficients on female between columns (1), which includes no occupational or task controls and (3), which includes both. This is due to the fact that we do do not directly account for male-female differences in task use in the first three columns. In columns (4) and (5) of Tables 11 - 13 we add a set of multiplicative dummies of tasks and gender (column (4) is without occupational fixed effects, column (5) with) to control for differing levels of task use intensity among men and women in different task dimensions. Moreover, we do not observe significant differences in remuneration for the same levels of task intensity in either Northern (Table 11) or Southern Europe (Table 12), since the coefficients on the multiplicative terms are not significantly different from zero. A certain level of gender discrimination is present in Eastern Europe (Table 13), where women are paid slightly less for identical task use in identical occupations (columns 4 and 5).

Overall, comparing the coefficient on female between column (1) and column (5) of Tables 11-13 we see that the baseline wage-gap is completely accounted for by differing male-female task profiles in Northern and Southern Europe. In fact, in Southern and Eastern Europe the coefficient on female becomes insignificant in column (5), and is significantly different from the large and negative estimate we see in column (1). In Northern Europe, the coefficient on female becomes positive and weakly significant and is significantly different from the estimate in column (1) of Table 11.

Overall, we can say that controlling for the differing levels of task use intensity is a good predictor of the gender wage-gap within occupations. In section 3 we provided evidence that women tended to be less intensively involved in almost all types of tasks and we've shown that a number of different mechanisms for that gap might be at play. In this section, we show that the gap in task use has some pass-through to gaps in wages within-occupations. Accounting for the task gap within occupations can account for the gender wage-gap within occupations that is observed in subsection 4.1 as well as in previous work. The question of why women appear to be less intensively involved in the day-to-day tasks of the jobs remains open, but is likely driven by number of different mechanisms that together compound small differences.

\section{Discussion}

Recent evidence from several developed countries suggests that a large proportion of the gender wagegap is found among men and women of not only identical education and experience levels, but also identical occupational titles. This finding calls for the study of possible male-female differences among individuals employed in the same occupations. A number of papers have zoomed into the day-to-day activities of American of men and women in specific professions such as academia (Babcock et al. (2017)) and law (Azmat and Ferrer (2017)) and have found significant gaps in job activities that translate into lower wages and worse career outcomes for women.

Nevertheless, little is known about the prevalence of task differences among men and women across different occupations and countries and their possible reverberations on the male-female wage gap. In this paper we provide evidence for a significant and persistent gaps in task use among men and women, whereby women appear to be less intensively involved than men in various types of job tasks. The gap in task use is partly related to fertility shocks and selection into the labour force in Northern European countries, but neither mechanism can completely account for the observed differences. The difference is also not accounted for by the number of hours worked, occupational segregation and it does not, a priori, appear to be the product of measurement error. The difference by gender in task use translates into a fully decomposable gender-wage gap in all countries of the sample, whereby taking 
into account differences in task intensity among those in the same occupation, we can account for the entirety of the within-occupational gender wage-gap. 


\section{References}

Angelov, N., P. Johansson, And E. Lindahl (2016): "Parenthood and the gender gap in pay," Journal of Labor Economics, 34, 545-579.

Autor, D. H. And M. J. Handel (2013): "Putting Tasks to the Test: Human Capital, Job Tasks, and Wages," Journal of Labor Economics, 31, S59-S96.

Azmat, G. And R. Ferrer (2017): "Gender gaps in performance: Evidence from young lawyers," Journal of Political Economy, 125, 1306-1355.

Babcock, L., M. P. Recalde, L. Vesterlund, and L. Weingart (2017): "Gender differences in accepting and receiving requests for tasks with low promotability," American Economic Review, $107,714-47$.

Barber, B. M. and T. Odean (2001): "Boys will be boys: Gender, overconfidence, and common stock investment," The quarterly journal of economics, 116, 261-292.

Bengtsson, C., M. Persson, And P. Willenhag (2005): "Gender and overconfidence," Economics letters, 86, 199-203.

Benschop, Y. And H. DoorewaArd (1998): "Covered by equality: The gender subtext of organizations," Organization Studies, 19, 787-805.

Bertrand, M., C. Goldin, And L. F. Katz (2010): "Dynamics of the gender gap for young professionals in the financial and corporate sectors," American Economic Journal: Applied Economics, $2,228-55$.

BEYER, S. (1990): "Gender differences in the accuracy of self-evaluations of performance." Journal of personality and social psychology, 59, 960.

Beyer, S. And E. M. Bowden (1997): "Gender differences in seff-perceptions: Convergent evidence from three measures of accuracy and bias," Personality and Social Psychology Bulletin, 23, 157-172.

Blau, F. D. and L. M. Kahn (2000): "Gender Differences in Pay," The Journal of Economic Perspectives, 14, 75-99.

Cobb-Clark, D. A. And M. TAN (2011): "Noncognitive skills, occupational attainment, and relative wages," Labour Economics, 18, 1-13.

De Pater, I. E., A. E. Van Vianen, and M. N. Bechtoldt (2010): "Gender differences in job challenge: A matter of task allocation," Gender, Work $\& 3$ Organization, 17, 433-453.

Gicheva, D. (2013): "Working Long Hours and Early Career Outcomes in the High-End Labor Market," Journal of Labor Economics, 31, 785-824.

Goldin, C. (2006): "The quiet revolution that transformed women's employment, education, and family," American economic review, 96, 1-21.

(2014): "A Grand Gender Convergence: Its Last Chapter," American Economic Review, 104, $1091-1119$ 
Groshen, E. (1991): "The Structure of the Female/Male Wage Differential: Is It Who You Are, What You Do, or Where You Work?" Journal of Human Resources, 26, 457-472.

KANTER, R. M. (2008): Men and women of the corporation: New edition, Basic books.

Kleven, H., C. Landais, and J. E. SøgaArd (2018): "Children and gender inequality: Evidence from Denmark," Tech. rep., National Bureau of Economic Research.

KorkeAmÄKI, O. AND T. KYYRÄ (2006): "A gender wage gap decomposition for matched employeremployee data," Labour Economics, 13, 611-638.

McCauley, C. D., M. N. Ruderman, P. J. Ohlott, and J. E. Morrow (1994): "Assessing the developmental components of managerial jobs." Journal of applied psychology, 79, 544.

Mulligan, C. B. And Y. Rubinstein (2008): "Selection, investment, and women's relative wages over time," The Quarterly Journal of Economics, 123, 1061-1110.

Olivetti, C. And B. Petrongolo (2008): "Unequal pay or unequal employment? A crosscountry analysis of gender gaps," Journal of Labor Economics, 26, 621-654.

Pekkarinen, T. (2012): "Gender differences in education," Nordic Economic Policy Review, 1, 165194.

Petö, R. And B. Reizer (2019): "Gender Differences in the Skill Content of Jobs," Mimeo.

PolacheK, S. (1981): "Occupational Self-Selection: A Human Capital Approach to Sex Differences in Occupational Structure," The Review of Economics and Statistics, 63, 60-69.

Sorensen, E. (1989): "Measuring the effect of Occupational Sex and Race Composition on Earnings," in Pay Equity: Empirical Enquiries, ed. by H. H. RT Michael and B. O'Farrell, Washington, DC: National Academy Press.

Williams, J. C. AND R. DemPSey (2018): What works for women at work: Four patterns working women need to know, NYU Press. 
Table 1: Summary Statistics

\begin{tabular}{lccccccccccccc}
\hline \hline & BEL & CZE & DNK & FRA & GRC & ITA & NLD & NOR & POL & SVK & SVN & ESP & UK \\
\hline Sample & 2,721 & 2,648 & 4,466 & 3,681 & 1,491 & 1,823 & 3,203 & 3,197 & 3,930 & 2,485 & 2,231 & 2,475 & 4,823 \\
Female & 0.479 & 0.501 & 0.488 & 0.480 & 0.502 & 0.439 & 0.480 & 50.45 & 0.427 & 0.474 & 0.494 & 0.467 & 0.582 \\
& & & & & & & & & & & & \\
ln(hourly wage) & & & & & & & & & & & & \\
Male & 2.93 & 2.14 & 3.13 & 2.70 & 2.21 & 2.64 & 2.93 & 3.19 & 1.96 & 2.03 & 2.13 & 2.56 & 2.83 \\
Female & 2.86 & 1.94 & 3.04 & 2.58 & 2.12 & 2.58 & 2.81 & 3.04 & 1.88 & 1.82 & 2.09 & 2.43 & 2.70 \\
& & & & & & & & & & & & & \\
Hours worked & & & & & & & & & & & & \\
Male & 43.22 & 42.66 & 38.63 & 40.23 & 46.59 & 41.42 & 37.91 & 46.59 & 42.77 & 43.60 & 42.92 & 41.22 & 39.92 \\
Female & 33.60 & 37.30 & 32.56 & 34.15 & 38.44 & 34.71 & 25.29 & 38.44 & 37.34 & 39.57 & 40.24 & 34.48 & 31.36 \\
& & & & & & & & & & & & \\
Activity Rates & & & & & & & & & & & & \\
Male & 0.723 & 0.787 & 0.823 & 0.746 & 0.772 & 0.646 & 0.832 & 0.799 & 0.727 & 0.766 & 0.739 & 0.676 & 0.815 \\
Female & 0.539 & 0.622 & 0.762 & 0.657 & 0.575 & 0.514 & 0.729 & 0.757 & 0.589 & 0.609 & 0.665 & 0.534 & 0.696 \\
& & & & & & & & & & & & \\
Yrs of Education & & & & & & & & & & & & \\
Male & 12.8 & 13.6 & 13.1 & 11.9 & 12.5 & 11.9 & 13.5 & 14.4 & 12.6 & 13.4 & 10.6 & 11.6 & 13.3 \\
Female & 13.1 & 13.7 & 13.4 & 12.3 & 13.1 & 13.1 & 13.5 & 14.6 & 13.9 & 13.9 & 11.3 & 12.4 & 13.4 \\
\hline \hline
\end{tabular}

We use hourly wage that is ppp-adjusted to allow for comparability between countries. The sample includes employed individuals only (no self-employed). Numbers for activity rates are taken from the OECD's Main Economic Indicators for the year 2011, which corresponds to the year of the PIAAC survey. 
Table 2: OLS regressions of Task Use at Work

\begin{tabular}{|c|c|c|c|c|c|c|c|}
\hline & $(1)$ & $(2)$ & $(3)$ & $(4)$ & $(5)$ & $(6)$ & $(7)$ \\
\hline & \multicolumn{7}{|c|}{ A. NORTHERN EUROPE } \\
\hline & Social & Management & Problem Solving & Literacy & Numeracy & ICT & Manual \\
\hline \multirow[t]{2}{*}{ female } & $-0.09^{* * *}$ & -0.02 & $-0.12^{* * *}$ & $-0.12^{* * *}$ & $-0.25^{* * *}$ & $-0.10^{* * *}$ & $0.09^{* * *}$ \\
\hline & $(0.01)$ & $(0.02)$ & $(0.02)$ & $(0.01)$ & $(0.01)$ & $(0.01)$ & $(0.02)$ \\
\hline \multirow[t]{2}{*}{ hours } & $0.01^{* * *}$ & $0.01^{* * *}$ & $0.01^{* * *}$ & $0.01^{* * *}$ & $0.01^{* * *}$ & $0.01^{* * *}$ & $0.01^{* * *}$ \\
\hline & $(0.00)$ & $(0.00)$ & $(0.00)$ & $(0.00)$ & $(0.00)$ & $(0.00)$ & $(0.00)$ \\
\hline$N$ & 20793 & 20776 & 20784 & 20792 & 20797 & 16750 & 20789 \\
\hline \multirow[t]{2}{*}{$R^{2}$} & 0.374 & 0.327 & 0.312 & 0.487 & 0.420 & 0.488 & 0.387 \\
\hline & \multicolumn{7}{|c|}{ B. SOUTHERN EUROPE } \\
\hline \multirow[t]{2}{*}{ female } & $-0.09 * * *$ & $-0.05^{* *}$ & $-0.15^{* * *}$ & $-0.15^{* * *}$ & $-0.16^{* * *}$ & $-0.09 * * *$ & $-0.06^{* *}$ \\
\hline & $(0.02)$ & $(0.02)$ & $(0.02)$ & $(0.01)$ & $(0.02)$ & $(0.02)$ & $(0.03)$ \\
\hline \multirow[t]{2}{*}{ hours } & $0.01^{* * *}$ & $0.01 * * *$ & $0.02^{* * *}$ & $0.01^{* * *}$ & $0.01 * * *$ & $0.01 * * *$ & $0.01^{* * *}$ \\
\hline & $(0.00)$ & $(0.00)$ & $(0.00)$ & $(0.00)$ & $(0.00)$ & $(0.00)$ & $(0.00)$ \\
\hline$N$ & 12941 & 12900 & 12878 & 12919 & 12925 & 7876 & 12922 \\
\hline \multirow[t]{2}{*}{$R^{2}$} & 0.379 & 0.251 & 0.254 & 0.532 & 0.428 & 0.414 & 0.390 \\
\hline & \multicolumn{7}{|c|}{ C. EASTERN EUROPE } \\
\hline \multirow[t]{2}{*}{ female } & $-0.12^{* * *}$ & $-0.26 * * *$ & $-0.24 * * *$ & $-0.19^{* * *}$ & $-0.16^{* * *}$ & $-0.17 * * *$ & $0.07 * * *$ \\
\hline & $(0.02)$ & $(0.02)$ & $(0.02)$ & $(0.01)$ & $(0.02)$ & $(0.02)$ & $(0.02)$ \\
\hline \multirow[t]{2}{*}{ hours } & $0.01^{* * *}$ & $0.01^{* * *}$ & $0.01^{* * *}$ & $0.01^{* * *}$ & $0.01^{* * *}$ & $0.01^{* * *}$ & $0.01^{* * *}$ \\
\hline & $(0.00)$ & $(0.00)$ & $(0.00)$ & $(0.00)$ & $(0.00)$ & $(0.00)$ & $(0.00)$ \\
\hline$N$ & 14812 & 14753 & 14761 & 14785 & 14797 & 9113 & 14787 \\
\hline$R^{2}$ & 0.379 & 0.325 & 0.252 & 0.515 & 0.429 & 0.446 & 0.446 \\
\hline Occupations & $\checkmark$ & $\checkmark$ & $\checkmark$ & $\checkmark$ & $\checkmark$ & $\checkmark$ & $\checkmark$ \\
\hline Human Capital & $\checkmark$ & $\checkmark$ & $\checkmark$ & $\checkmark$ & $\checkmark$ & $\checkmark$ & $\checkmark$ \\
\hline Country Dummies & $\checkmark$ & $\checkmark$ & $\checkmark$ & $\checkmark$ & $\checkmark$ & $\checkmark$ & $\checkmark$ \\
\hline
\end{tabular}

Occupation controls include 264 dummies. Human Capital controls include 3 education levels (less than high school, high school and tertiary education, where high school is the reference category); experience and experience squared; whether the individual is native speaker. Country dummies are different for each panel: in Panel A I include Belgium, Denmark, the Netherlands, Norway and the UK; in Panel B I include France, Greece, Italy and Spain; in Panel C I include Czechia, Slovenia, Slovakia and Poland. The sample is restricted to employed individuals between 16-64 only (no self-employed). We run OLS regressions where the dependent variable is a continuous variable from $1-5 .{ }^{*} p<0.10,{ }^{* *} p<0.05,{ }^{* * *} p<0.01$ 
Table 3: Effect of Fertility on Task Use at work - Northern Europe

\begin{tabular}{|c|c|c|c|c|c|c|c|}
\hline & \multicolumn{7}{|c|}{ Northern Europe } \\
\hline & (1) & $(2)$ & $(3)$ & (4) & $(5)$ & $(6)$ & $(7)$ \\
\hline & Social & Management & Problem Sovling & Literacy & Numeracy & ICT & Manual \\
\hline \multirow[t]{2}{*}{ Female } & $-0.10^{* * *}$ & 0.02 & $-0.09^{* * *}$ & $-0.11^{* * *}$ & $-0.20^{* * *}$ & $-0.10^{* * *}$ & 0.03 \\
\hline & $(0.02)$ & $(0.03)$ & $(0.03)$ & $(0.02)$ & $(0.02)$ & $(0.02)$ & $(0.04)$ \\
\hline \multirow[t]{2}{*}{ Female $* 1$ child } & 0.01 & -0.06 & -0.04 & -0.03 & -0.01 & 0.03 & 0.04 \\
\hline & $(0.03)$ & $(0.05)$ & $(0.04)$ & $(0.03)$ & $(0.04)$ & $(0.03)$ & $(0.05)$ \\
\hline \multirow[t]{2}{*}{ Female $* 2$ children } & -0.02 & -0.06 & -0.03 & -0.01 & $-0.08^{* *}$ & -0.01 & $0.11^{* *}$ \\
\hline & $(0.03)$ & $(0.04)$ & $(0.04)$ & $(0.02)$ & $(0.03)$ & $(0.03)$ & $(0.05)$ \\
\hline \multirow[t]{2}{*}{ Female $* 3$ children } & 0.00 & $-0.10^{* *}$ & $-0.10^{* *}$ & -0.03 & $-0.19^{* * *}$ & $-0.08 * *$ & $0.21^{* * *}$ \\
\hline & $(0.03)$ & $(0.05)$ & $(0.04)$ & $(0.03)$ & $(0.04)$ & $(0.03)$ & $(0.06)$ \\
\hline \multirow[t]{2}{*}{ Female $* \geq 4$ children } & 0.04 & -0.05 & -0.02 & -0.03 & 0.01 & 0.03 & 0.01 \\
\hline & $(0.03)$ & $(0.05)$ & $(0.04)$ & $(0.03)$ & $(0.04)$ & $(0.03)$ & $(0.06)$ \\
\hline \multirow[t]{2}{*}{1 child } & $0.05^{* *}$ & $0.15^{* * *}$ & 0.03 & $0.07^{* * *}$ & 0.03 & 0.03 & -0.01 \\
\hline & $(0.02)$ & $(0.03)$ & $(0.03)$ & $(0.02)$ & $(0.03)$ & $(0.02)$ & $(0.04)$ \\
\hline \multirow[t]{2}{*}{2 children } & $0.04^{* *}$ & $0.18^{* * *}$ & -0.01 & $0.07 * * *$ & $0.07^{* * *}$ & $0.05^{* *}$ & $-0.09^{* * *}$ \\
\hline & $(0.02)$ & $(0.03)$ & $(0.03)$ & $(0.02)$ & $(0.02)$ & $(0.02)$ & $(0.03)$ \\
\hline \multirow[t]{2}{*}{3 children } & $0.05^{* *}$ & $0.21^{* * *}$ & 0.04 & $0.09^{* * *}$ & $0.16^{* * *}$ & $0.09^{* * *}$ & $-0.13^{* * *}$ \\
\hline & $(0.02)$ & $(0.04)$ & $(0.03)$ & $(0.02)$ & $(0.03)$ & $(0.03)$ & $(0.04)$ \\
\hline \multirow[t]{2}{*}{$\geq 4$ children } & 0.03 & $0.16^{* * *}$ & -0.01 & $0.07 * * *$ & 0.03 & 0.02 & -0.00 \\
\hline & $(0.03)$ & $(0.04)$ & $(0.03)$ & $(0.02)$ & $(0.03)$ & $(0.03)$ & $(0.04)$ \\
\hline$N$ & 20790 & 20774 & 20782 & 20790 & 20795 & 16749 & 20787 \\
\hline$R^{2}$ & 0.375 & 0.328 & 0.313 & 0.488 & 0.421 & 0.488 & 0.388 \\
\hline Occupations & $\bar{l} \checkmark$ & $\bar{\nabla} \checkmark$ & $\bar{\nabla} \checkmark$ & $\bar{l} \checkmark$ & $\bar{\checkmark} \checkmark$ & $\bar{\nabla} \checkmark$ & $\bar{\nabla} \checkmark$ \\
\hline Human Capital & $\checkmark$ & $\checkmark$ & $\checkmark$ & $\checkmark$ & $\checkmark$ & $\checkmark$ & $\checkmark$ \\
\hline Country Dummies & $\checkmark$ & $\checkmark$ & $\checkmark$ & $\checkmark$ & $\checkmark$ & $\checkmark$ & $\checkmark$ \\
\hline
\end{tabular}

Occupation controls include 264 dummies. Human Capital controls include 3 education levels (less than high school, high school and tertiary education, where high school is the reference category); experience and experience squared; whether the individual is native speaker; hours worked. Country dummies for Northern Europe are Belgium, Denmark, The Netherlands, Norway, the UK. The sample is restricted to employed individuals between 16-64 only (no self-employed). We run OLS regressions where the dependent variable is a continuous variable from $1-5 .{ }^{*} p<0.10,{ }^{* *} p<0.05,{ }^{* * *} p<0.01$ 
Table 4: Effect of Fertility on Task Use at work - Southern Europe

\begin{tabular}{|c|c|c|c|c|c|c|c|}
\hline & \multicolumn{7}{|c|}{ Southern Europe } \\
\hline & (1) & $(2)$ & $(3)$ & (4) & $(5)$ & (6) & (7) \\
\hline & Social & Management & Problem Sovling & Literacy & Numeracy & ICT & Manual \\
\hline \multirow[t]{2}{*}{ Female } & -0.03 & -0.04 & $-0.12^{* * *}$ & $-0.11 * * *$ & $-0.15^{* * *}$ & -0.04 & -0.03 \\
\hline & $(0.02)$ & $(0.04)$ & $(0.03)$ & $(0.02)$ & $(0.03)$ & $(0.03)$ & $(0.04)$ \\
\hline \multirow[t]{2}{*}{ Female $^{*} 1$ child } & $-0.06^{*}$ & -0.05 & -0.00 & $-0.07 * *$ & -0.05 & $-0.11 * *$ & 0.05 \\
\hline & $(0.04)$ & $(0.06)$ & $(0.05)$ & $(0.03)$ & $(0.04)$ & $(0.05)$ & $(0.06)$ \\
\hline \multirow[t]{2}{*}{ Female $* 2$ children } & $-0.12^{* * *}$ & -0.05 & -0.04 & $-0.07^{* *}$ & 0.00 & $-0.07^{*}$ & -0.07 \\
\hline & $(0.03)$ & $(0.05)$ & $(0.05)$ & $(0.03)$ & $(0.04)$ & $(0.04)$ & $(0.05)$ \\
\hline \multirow[t]{2}{*}{ Female $* 3$ children } & $-0.14^{* * *}$ & 0.02 & $-0.13^{*}$ & -0.01 & -0.01 & -0.04 & -0.06 \\
\hline & $(0.05)$ & $(0.07)$ & $(0.07)$ & $(0.04)$ & $(0.05)$ & $(0.06)$ & $(0.08)$ \\
\hline \multirow[t]{2}{*}{ Female $^{*} \geq 4$ children } & $-0.14^{* *}$ & -0.06 & -0.16 & -0.00 & -0.05 & -0.05 & $-0.29^{* *}$ \\
\hline & $(0.07)$ & $(0.11)$ & $(0.11)$ & $(0.07)$ & $(0.08)$ & $(0.11)$ & $(0.12)$ \\
\hline \multirow[t]{2}{*}{1 child } & 0.04 & $0.10^{* *}$ & 0.04 & 0.02 & 0.05 & 0.02 & -0.06 \\
\hline & $(0.03)$ & $(0.04)$ & $(0.04)$ & $(0.02)$ & $(0.03)$ & $(0.03)$ & $(0.04)$ \\
\hline \multirow[t]{2}{*}{2 children } & $0.08^{* * *}$ & $0.13^{* * *}$ & 0.00 & $0.06^{* * *}$ & 0.04 & 0.03 & -0.01 \\
\hline & $(0.02)$ & $(0.04)$ & $(0.03)$ & $(0.02)$ & $(0.03)$ & $(0.03)$ & $(0.04)$ \\
\hline \multirow[t]{2}{*}{3 children } & 0.04 & $0.10^{*}$ & -0.05 & 0.03 & 0.03 & 0.04 & -0.03 \\
\hline & $(0.03)$ & $(0.05)$ & $(0.05)$ & $(0.03)$ & $(0.04)$ & $(0.04)$ & $(0.06)$ \\
\hline \multirow[t]{2}{*}{$\geq 4$ children } & 0.01 & $0.15^{* *}$ & -0.04 & 0.01 & -0.01 & -0.00 & 0.08 \\
\hline & $(0.05)$ & $(0.07)$ & $(0.07)$ & $(0.04)$ & $(0.06)$ & $(0.07)$ & $(0.08)$ \\
\hline$N$ & 12931 & 12890 & 12868 & 12909 & 12915 & 7869 & 12912 \\
\hline$R^{2}$ & 0.381 & 0.253 & 0.256 & 0.532 & 0.428 & 0.415 & 0.390 \\
\hline Occupations & 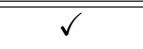 & 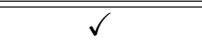 & 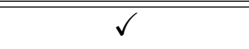 & 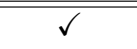 & 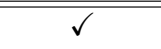 & 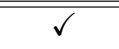 & 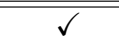 \\
\hline Human Capital & $\checkmark$ & $\checkmark$ & $\checkmark$ & $\checkmark$ & $\checkmark$ & $\checkmark$ & $\checkmark$ \\
\hline Country Dummies & $\checkmark$ & $\checkmark$ & $\checkmark$ & $\checkmark$ & $\checkmark$ & $\checkmark$ & $\checkmark$ \\
\hline
\end{tabular}

Occupation controls include 264 dummies. Human Capital controls include 3 education levels (less than high school, high school and tertiary education, where high school is the reference category); experience and experience squared; whether the individual is native speaker; hours worked. Country dummies for Southern Europe are France, Greece, Italy, Spain. The sample is restricted to employed individuals between 16-64 only (no self-employed). We run OLS regressions where the dependent variable is a continuous variable from $1-5 .{ }^{*} p<0.10,{ }^{* *} p<0.05,{ }^{* * *} p<0.01$ 
Table 5: Effect of Fertility on Task Use at work - Eastern Europe

\begin{tabular}{|c|c|c|c|c|c|c|c|}
\hline & \multicolumn{7}{|c|}{ Eastern Europe } \\
\hline & (1) & $(2)$ & (3) & (4) & $(5)$ & (6) & $(7)$ \\
\hline & Social & Management & Problem Sovling & Literacy & Numeracy & ICT & Manual \\
\hline \multirow[t]{2}{*}{ Female } & $-0.09^{* * *}$ & $-0.22^{* * *}$ & $-0.20^{* * *}$ & $-0.19^{* * *}$ & $-0.13^{* * *}$ & $-0.15^{* * *}$ & 0.01 \\
\hline & $(0.02)$ & $(0.03)$ & $(0.03)$ & $(0.02)$ & $(0.03)$ & $(0.03)$ & $(0.03)$ \\
\hline \multirow[t]{2}{*}{ Female $^{*} 1$ child } & -0.04 & -0.04 & -0.01 & -0.01 & $-0.07^{*}$ & -0.03 & $0.12^{* *}$ \\
\hline & $(0.03)$ & $(0.05)$ & $(0.05)$ & $(0.03)$ & $(0.04)$ & $(0.04)$ & $(0.05)$ \\
\hline \multirow[t]{2}{*}{ Female $* 2$ children } & $-0.05^{*}$ & $-0.08^{*}$ & $-0.08^{*}$ & 0.01 & -0.03 & -0.03 & $0.07^{*}$ \\
\hline & $(0.03)$ & $(0.04)$ & $(0.04)$ & $(0.03)$ & $(0.03)$ & $(0.04)$ & $(0.04)$ \\
\hline \multirow[t]{2}{*}{ Female $* 3$ children } & $-0.07^{*}$ & -0.11 & -0.06 & -0.01 & -0.07 & -0.09 & 0.09 \\
\hline & $(0.04)$ & $(0.07)$ & $(0.07)$ & $(0.04)$ & $(0.05)$ & $(0.06)$ & $(0.07)$ \\
\hline \multirow{2}{*}{ Female $^{*} \geq 4$ children } & -0.02 & $-0.26^{* *}$ & -0.15 & -0.03 & -0.04 & -0.07 & 0.17 \\
\hline & $(0.07)$ & $(0.11)$ & $(0.11)$ & $(0.07)$ & $(0.09)$ & $(0.11)$ & $(0.11)$ \\
\hline \multirow[t]{2}{*}{1 child } & -0.01 & 0.02 & -0.04 & 0.02 & $0.09 * * *$ & 0.03 & -0.04 \\
\hline & $(0.02)$ & $(0.04)$ & $(0.04)$ & $(0.02)$ & $(0.03)$ & $(0.03)$ & $(0.04)$ \\
\hline \multirow[t]{2}{*}{2 children } & 0.03 & $0.15^{* * *}$ & 0.01 & 0.01 & $0.07 * * *$ & 0.01 & 0.01 \\
\hline & $(0.02)$ & $(0.04)$ & $(0.03)$ & $(0.02)$ & $(0.03)$ & $(0.03)$ & $(0.03)$ \\
\hline \multirow[t]{2}{*}{3 children } & 0.04 & $0.13^{* *}$ & -0.02 & 0.03 & $0.10^{* *}$ & 0.03 & $0.12^{* *}$ \\
\hline & $(0.03)$ & $(0.05)$ & $(0.05)$ & $(0.03)$ & $(0.04)$ & $(0.05)$ & $(0.05)$ \\
\hline \multirow[t]{2}{*}{4 children } & -0.03 & $0.14^{*}$ & -0.03 & -0.02 & 0.05 & 0.07 & 0.05 \\
\hline & $(0.05)$ & $(0.08)$ & $(0.07)$ & $(0.05)$ & $(0.06)$ & $(0.08)$ & $(0.07)$ \\
\hline$N$ & 14790 & 14732 & 14739 & 14763 & 14775 & 9099 & 14765 \\
\hline$R^{2}$ & 0.380 & 0.327 & 0.253 & 0.515 & 0.429 & 0.446 & 0.447 \\
\hline Occupations & $\bar{\nabla} \checkmark$ & $\bar{l} \checkmark$ & $\bar{\nabla} \checkmark$ & $\bar{\nabla} \checkmark$ & 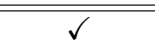 & $\bar{\nabla} \checkmark$ & $\bar{\nabla} \checkmark$ \\
\hline Human Capital & $\checkmark$ & $\checkmark$ & $\checkmark$ & $\checkmark$ & $\checkmark$ & $\checkmark$ & $\checkmark$ \\
\hline Country Dummies & $\checkmark$ & $\checkmark$ & $\checkmark$ & $\checkmark$ & $\checkmark$ & $\checkmark$ & $\checkmark$ \\
\hline
\end{tabular}

Occupation controls include 264 dummies. Human Capital controls include 3 education levels (less than high school, high school and tertiary education, where high school is the reference category); experience and experience squared; whether the individual is native speaker; hours worked. Country dummies for Eastern Europe are Czechia, Poland, Slovakia, Slovenia. The sample is restricted to employed individuals between 16-64 only (no self-employed). We run OLS regressions where the dependent variable is a continuous variable from $1-5 .{ }^{*} p<0.10,{ }^{* *} p<0.05,{ }^{* * *} p<0.01$ 
Table 6: Task Intensity by Age - Northern Europe

\begin{tabular}{lccccccc}
\hline & \multicolumn{7}{c}{ Northern Europe } \\
& $(1)$ & $(2)$ & $(3)$ & $(4)$ & $(5)$ & $(6)$ & $(7)$ \\
& Social & Management & Problem Sovling & Literacy & Numeracy & ICT & Manual \\
\hline Female & $-0.11^{* * *}$ & 0.02 & $-0.15^{* * *}$ & $-0.13^{* * *}$ & $-0.23^{* * *}$ & $-0.10^{* * *}$ & 0.02 \\
& $(0.02)$ & $(0.03)$ & $(0.03)$ & $(0.02)$ & $(0.03)$ & $(0.02)$ & $(0.04)$ \\
Age=16-24 & 0.00 & $-0.24^{* * *}$ & -0.06 & $-0.11^{* * *}$ & $-0.09^{* * *}$ & $-0.12^{* * *}$ & $0.09^{*}$ \\
& $(0.03)$ & $(0.04)$ & $(0.04)$ & $(0.02)$ & $(0.03)$ & $(0.03)$ & $(0.05)$ \\
Age=35-44 & $-0.09^{* * *}$ & -0.04 & $-0.18^{* * *}$ & $-0.09^{* * *}$ & -0.03 & $-0.07^{* * *}$ & $-0.16^{* * *}$ \\
& $(0.02)$ & $(0.03)$ & $(0.03)$ & $(0.02)$ & $(0.03)$ & $(0.02)$ & $(0.04)$ \\
Age=45-54 & $-0.23^{* * *}$ & $-0.23^{* * *}$ & $-0.31^{* * *}$ & $-0.21^{* * *}$ & $-0.14^{* * *}$ & $-0.17^{* * *}$ & $-0.23^{* * *}$ \\
& $(0.03)$ & $(0.04)$ & $(0.04)$ & $(0.02)$ & $(0.03)$ & $(0.03)$ & $(0.05)$ \\
Age=55-64 & $-0.32^{* * *}$ & $-0.31^{* * *}$ & $-0.40^{* * *}$ & $-0.24^{* * *}$ & $-0.17^{* * *}$ & $-0.21^{* * *}$ & $-0.36^{* * *}$ \\
& $(0.03)$ & $(0.05)$ & $(0.05)$ & $(0.03)$ & $(0.04)$ & $(0.04)$ & $(0.06)$ \\
Female*Age=16-24 & 0.05 & 0.04 & 0.06 & 0.03 & $0.17^{* * *}$ & 0.03 & 0.00 \\
& $(0.04)$ & $(0.05)$ & $(0.05)$ & $(0.03)$ & $(0.04)$ & $(0.04)$ & $(0.06)$ \\
Female*Age=35-44 & 0.00 & -0.06 & 0.04 & -0.01 & -0.04 & -0.00 & 0.05 \\
& $(0.03)$ & $(0.04)$ & $(0.04)$ & $(0.03)$ & $(0.03)$ & $(0.03)$ & $(0.05)$ \\
Female*Age=45-54 & 0.05 & -0.07 & 0.06 & $0.05^{*}$ & -0.03 & 0.01 & $0.14^{* * *}$ \\
& $(0.03)$ & $(0.04)$ & $(0.04)$ & $(0.03)$ & $(0.03)$ & $(0.03)$ & $(0.05)$ \\
Female*Age=55-64 & 0.01 & $-0.09^{*}$ & 0.00 & -0.05 & $-0.15^{* * *}$ & $-0.05^{*}$ & $0.21^{* * *}$ \\
& $(0.03)$ & $(0.05)$ & $(0.04)$ & $(0.03)$ & $(0.04)$ & $(0.03)$ & $(0.05)$ \\
\hline$N$ & 20793 & 20776 & 20784 & 20792 & 20797 & 16750 & 20789 \\
$R^{2}$ & 0.375 & 0.326 & 0.312 & 0.484 & 0.420 & 0.488 & 0.389 \\
\hline \hline Occupations & $\checkmark$ & $\checkmark$ & $\checkmark$ & $\checkmark$ & $\checkmark$ & $\checkmark$ & $\checkmark$ \\
Human Capital & $\checkmark$ & $\checkmark$ & $\checkmark$ & $\checkmark$ & $\checkmark$ & $\checkmark$ & $\checkmark$ \\
Country Dummies & $\checkmark$ & $\checkmark$ & $\checkmark$ & $\checkmark$ & $\checkmark$ & $\checkmark$ & $\checkmark$ \\
\hline
\end{tabular}

Occupation controls include 264 dummies. Human Capital controls include 3 education levels (less than high school, high school and tertiary education, where high school is the reference category); experience and experience squared; whether the individual is native speaker; hours worked. For Northern Europe, country dummies are Belgium, Denmark, the Netherlands, Norway, the UK. The sample is restricted to employed individuals between 16-64 only (no self-employed). We run OLS regressions where the dependent variable is a continuous variable from $1-5 .{ }^{*} p<0.10,{ }^{* *} p<0.05,{ }^{* * *} p<0.01$ 
Table 7: Task Intensity by Age - Southern Europe

\begin{tabular}{lccccccc}
\hline & \multicolumn{7}{c}{ Southern Europe } \\
\hline & $(1)$ & $(2)$ & $(3)$ & $(4)$ & $(5)$ & $(6)$ & $(7)$ \\
& Social & Management & Problem Sovling & Literacy & Numeracy & ICT & Manual \\
\hline Female & $-0.11^{* * *}$ & -0.05 & $-0.13^{* * *}$ & $-0.17^{* * *}$ & $-0.14^{* * *}$ & $-0.08^{* *}$ & $-0.09^{*}$ \\
& $(0.03)$ & $(0.04)$ & $(0.04)$ & $(0.03)$ & $(0.03)$ & $(0.04)$ & $(0.05)$ \\
Age16-24 & 0.03 & $-0.11^{*}$ & -0.08 & -0.03 & -0.05 & $-0.13^{* *}$ & 0.07 \\
& $(0.04)$ & $(0.06)$ & $(0.06)$ & $(0.04)$ & $(0.05)$ & $(0.06)$ & $(0.07)$ \\
Age35-44 & $-0.12^{* * *}$ & -0.02 & $-0.07^{*}$ & -0.01 & $-0.07^{* *}$ & -0.03 & $-0.14^{* * *}$ \\
& $(0.03)$ & $(0.04)$ & $(0.04)$ & $(0.03)$ & $(0.03)$ & $(0.04)$ & $(0.05)$ \\
Age45-54 & $-0.23^{* * *}$ & $-0.10^{* *}$ & $-0.15^{* * *}$ & $-0.07^{* *}$ & $-0.16^{* * *}$ & $-0.11^{* *}$ & $-0.21^{* * *}$ \\
& $(0.03)$ & $(0.05)$ & $(0.05)$ & $(0.03)$ & $(0.04)$ & $(0.04)$ & $(0.05)$ \\
Age55-64 & $-0.37^{* * *}$ & $-0.14^{* *}$ & $-0.32^{* * *}$ & $-0.16^{* * *}$ & $-0.18^{* * *}$ & $-0.22^{* * *}$ & $-0.22^{* * *}$ \\
& $(0.04)$ & $(0.06)$ & $(0.06)$ & $(0.04)$ & $(0.05)$ & $(0.06)$ & $(0.07)$ \\
Female*Age16-24 & 0.04 & 0.01 & -0.03 & 0.02 & -0.01 & 0.12 & -0.11 \\
& $(0.06)$ & $(0.09)$ & $(0.08)$ & $(0.05)$ & $(0.07)$ & $(0.08)$ & $(0.10)$ \\
Female*Age35-44 & 0.06 & 0.01 & 0.01 & 0.02 & -0.01 & -0.02 & 0.03 \\
& $(0.04)$ & $(0.06)$ & $(0.05)$ & $(0.03)$ & $(0.04)$ & $(0.05)$ & $(0.06)$ \\
Female*Age45-54 & 0.04 & 0.02 & -0.03 & 0.03 & -0.01 & -0.01 & $0.11^{*}$ \\
& $(0.04)$ & $(0.06)$ & $(0.06)$ & $(0.04)$ & $(0.04)$ & $(0.05)$ & $(0.06)$ \\
Female*Age55-64 & -0.01 & -0.07 & -0.03 & 0.05 & $-0.11^{* *}$ & 0.00 & 0.07 \\
& $(0.05)$ & $(0.07)$ & $(0.07)$ & $(0.04)$ & $(0.05)$ & $(0.06)$ & $(0.08)$ \\
\hline$N$ & 12941 & 12900 & 12878 & 12919 & 12925 & 7876 & 12922 \\
$R^{2}$ & 0.381 & 0.248 & 0.252 & 0.521 & 0.425 & 0.412 & 0.391 \\
\hline \hline Occupations & $\checkmark$ & $\checkmark$ & $\checkmark$ & $\checkmark$ & $\checkmark$ & $\checkmark$ & $\checkmark$ \\
Human Capital & $\checkmark$ & $\checkmark$ & $\checkmark$ & $\checkmark$ & $\checkmark$ & $\checkmark$ & $\checkmark$ \\
Country Dummies & $\checkmark$ & $\checkmark$ & $\checkmark$ & $\checkmark$ & $\checkmark$ & $\checkmark$ & $\checkmark$ \\
\hline
\end{tabular}

Occupation controls include 264 dummies. Human Capital controls include 3 education levels (less than high school, high school and tertiary education, where high school is the reference category); experience and experience squared; whether the individual is native speaker; hours worked. For Southern Europe, country dummies are France, Italy, Greece, Spain. The sample is restricted to employed individuals between 16-64 only (no self-employed). We run OLS regressions where the dependent variable is a continuous variable from $1-5 .{ }^{*} p<0.10,{ }^{* *} p<0.05,{ }^{* * *} p<0.01$ 
Table 8: Task Intensity by Age - Eastern Europe

\begin{tabular}{lccccccc}
\hline & \multicolumn{7}{c}{ Eastern Europe } \\
& $(1)$ & $(2)$ & $(3)$ & $(4)$ & $(5)$ & $(6)$ & $(7)$ \\
& Social & Management & Problem Sovling & Literacy & Numeracy & ICT & Manual \\
\hline Female & $-0.10^{* * *}$ & $-0.20^{* * *}$ & $-0.17^{* * *}$ & $-0.20^{* * *}$ & $-0.17^{* * *}$ & $-0.19^{* * *}$ & 0.06 \\
& $(0.02)$ & $(0.04)$ & $(0.04)$ & $(0.02)$ & $(0.03)$ & $(0.03)$ & $(0.04)$ \\
Age16-24 & $0.07^{* * *}$ & 0.06 & $0.08^{* *}$ & 0.03 & -0.02 & -0.03 & 0.04 \\
& $(0.03)$ & $(0.04)$ & $(0.04)$ & $(0.02)$ & $(0.03)$ & $(0.04)$ & $(0.04)$ \\
Age35-44 & $-0.11^{* * *}$ & -0.00 & $-0.10^{* *}$ & $-0.11^{* * *}$ & $-0.06^{*}$ & -0.03 & 0.04 \\
& $(0.03)$ & $(0.04)$ & $(0.04)$ & $(0.03)$ & $(0.03)$ & $(0.04)$ & $(0.04)$ \\
Age45-54 & $-0.19^{* * *}$ & $-0.13^{* *}$ & $-0.16^{* * *}$ & $-0.20^{* * *}$ & $-0.13^{* * *}$ & -0.08 & 0.05 \\
& $(0.04)$ & $(0.06)$ & $(0.05)$ & $(0.03)$ & $(0.04)$ & $(0.05)$ & $(0.05)$ \\
Age55-64 & $-0.22^{* * *}$ & $-0.13^{*}$ & $-0.23^{* * *}$ & $-0.25^{* * *}$ & $-0.21^{* * *}$ & $-0.14^{* *}$ & -0.06 \\
& $(0.05)$ & $(0.07)$ & $(0.07)$ & $(0.04)$ & $(0.06)$ & $(0.07)$ & $(0.07)$ \\
Female*Age16-24 & -0.01 & $-0.12^{* *}$ & $-0.12^{* *}$ & -0.05 & 0.02 & 0.03 & -0.05 \\
& $(0.04)$ & $(0.06)$ & $(0.05)$ & $(0.03)$ & $(0.04)$ & $(0.05)$ & $(0.05)$ \\
Female*Age35-44 & 0.01 & -0.07 & -0.05 & 0.04 & 0.03 & 0.02 & 0.03 \\
& $(0.03)$ & $(0.05)$ & $(0.05)$ & $(0.03)$ & $(0.04)$ & $(0.04)$ & $(0.05)$ \\
Female*Age45-54 & -0.02 & -0.07 & $-0.10^{* *}$ & 0.03 & 0.01 & -0.01 & 0.03 \\
& $(0.03)$ & $(0.05)$ & $(0.05)$ & $(0.03)$ & $(0.04)$ & $(0.04)$ & $(0.05)$ \\
Female*Age55-64 & -0.04 & -0.05 & $-0.12^{* *}$ & 0.06 & 0.05 & 0.06 & 0.07 \\
& $(0.04)$ & $(0.06)$ & $(0.06)$ & $(0.04)$ & $(0.05)$ & $(0.05)$ & $(0.06)$ \\
\hline$N$ & 14812 & 14753 & 14761 & 14785 & 14797 & 9113 & 14787 \\
$R^{2}$ & 0.379 & 0.323 & 0.251 & 0.512 & 0.427 & 0.445 & 0.447 \\
\hline \hline Occupations & $\checkmark$ & $\checkmark$ & $\checkmark$ & $\checkmark$ & $\checkmark$ & $\checkmark$ & $\checkmark$ \\
Human Capital & $\checkmark$ & $\checkmark$ & $\checkmark$ & $\checkmark$ & $\checkmark$ & $\checkmark$ & $\checkmark$ \\
Country Dummies & $\checkmark$ & $\checkmark$ & $\checkmark$ & $\checkmark$ & $\checkmark$ & $\checkmark$ & $\checkmark$ \\
\hline
\end{tabular}

Occupation controls include 264 dummies. Human Capital controls include 3 education levels (less than high school, high school and tertiary education, where high school is the reference category); experience and experience squared; whether the individual is native speaker; hours worked. For Eastern Europe, country dummies are Czechia, Poland, Slovenia, Slovakia. The sample is restricted to employed individuals between 16-64 only (no self-employed). We run OLS regressions where the dependent variable is a continuous variable from $1-5 .{ }^{*} p<0.10,{ }^{* *} p<0.05,{ }^{* * *} p<0.01$ 
Table 9: Task Intensity in the Public versus the Private Sector

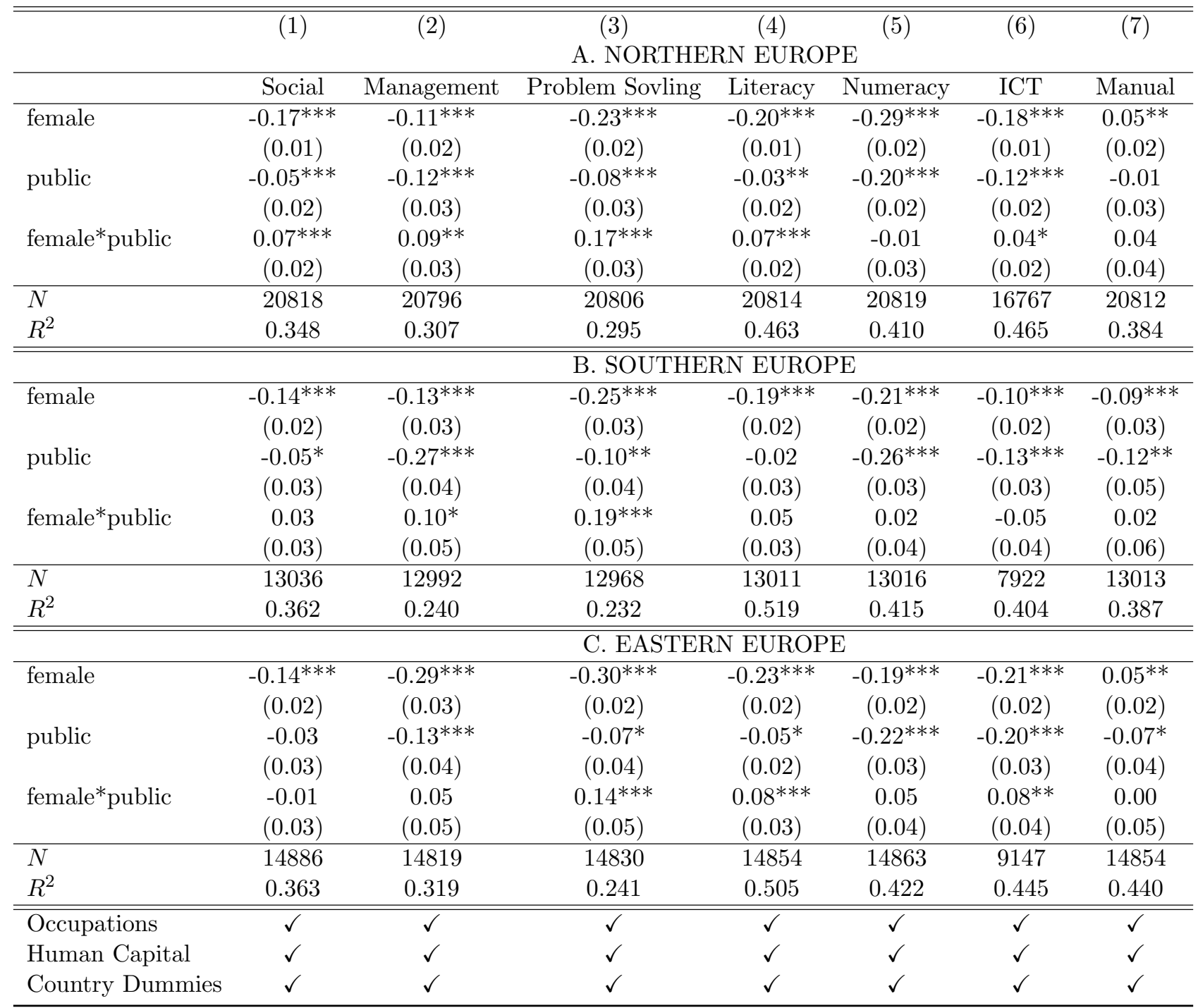

Occupation controls include 256 dummies. Human Capital controls include 3 education levels (less than high school, high school and tertiary education), where high school is the reference category; experience and experience squared; whether the individual is native speaker; hours worked. Country dummies are different for each panel: in Panel A I include Belgium, Denmark, the Netherlands, Norway and the UK; in Panel B I include France and Italy, Greece and Spain; in Panel C I include Czechia, Poland, Slovakia, Slovenia. The sample is restricted to employed individuals between 16-64 only (no self-employed). We run OLS regressions where the dependent variable is a continuous variable from $1-5 .{ }^{*} p<0.10,{ }^{* *} p<0.05,{ }^{* * *} p<0.01$ 
Table 10: Effect of occupations on the female coefficient on hourly wage

\begin{tabular}{|c|c|c|c|c|}
\hline Sample & Variables & $\begin{array}{l}\text { Coefficient } \\
\text { on female }\end{array}$ & SE & $R^{2}$ \\
\hline \multicolumn{5}{|c|}{ Northern Europe } \\
\hline Full-time & Basic & -0.09 & 0.02 & 0.20 \\
\hline Full-time & Basic, hours & -0.10 & 0.01 & 0.20 \\
\hline Full-time & Basic, hours, education & -0.14 & 0.01 & 0.34 \\
\hline Full-time & Basic, hours, education, occupation & -0.09 & 0.01 & 0.44 \\
\hline All & Basic & -0.11 & 0.01 & 0.26 \\
\hline All & Basic, hours & -0.11 & 0.01 & 0.26 \\
\hline All & Basic, hours, education & -0.13 & 0.01 & 0.37 \\
\hline All & Basic, hours, education, occupation & -0.08 & 0.01 & 0.45 \\
\hline \multicolumn{5}{|c|}{ Southern Europe } \\
\hline Full-time & Basic & -0.09 & 0.02 & 0.17 \\
\hline Full-time & Basic, hours & -0.13 & 0.02 & 0.24 \\
\hline Full-time & Basic, hours, education & -0.19 & 0.02 & 0.41 \\
\hline Full-time & Basic, hours, education, occupation & -0.10 & 0.01 & 0.49 \\
\hline All & Basic & -0.10 & 0.02 & 0.18 \\
\hline All & Basic, hours & -0.15 & 0.02 & 0.21 \\
\hline All & Basic, hours, education & -0.20 & 0.02 & 0.38 \\
\hline All & Basic, hours, education, occupation & -0.09 & 0.01 & 0.45 \\
\hline \multicolumn{5}{|c|}{ Eastern Europe } \\
\hline Full-time & Basic & -0.16 & 0.04 & 0.06 \\
\hline Full-time & Basic, hours & -0.20 & 0.05 & 0.10 \\
\hline Full-time & Basic, hours, education & -0.26 & 0.03 & 0.22 \\
\hline Full-time & Basic, hours, education, occupation & -0.17 & 0.02 & 0.28 \\
\hline All & Basic & -0.16 & 0.04 & 0.07 \\
\hline All & Basic, hours & -0.20 & 0.04 & 0.10 \\
\hline All & Basic, hours, education & -0.26 & 0.03 & 0.20 \\
\hline All & Basic, hours, education, occupation & -0.16 & 0.02 & 0.27 \\
\hline
\end{tabular}

Each line is a separate regression from which we only keep the coefficient on female. The dependent variable is the ppp-corrected log of hourly earnings. 'Basic' contains the controls female, an age quartic, a dummy for whether the individual is a native speaker and dummies for the different countries in the sample. We then gradually add more controls: hours; education dummies; and finally occupational fixed effects at the 4-digit levels. 'Full-time' refers to those working full-time only; 'All' refers to those working full-time or part-time. Standard errors are clustered at the country level, to follow the sampling design. 
Table 11: OLS Regressions of Log Hourly wage on Tasks and Gender - Northern Europe

\begin{tabular}{|c|c|c|c|c|c|}
\hline & (1) & $(2)$ & $(3)$ & (4) & $(5)$ \\
\hline female & $\begin{array}{c}-0.12^{* * *} \\
(0.01)\end{array}$ & $\begin{array}{c}-0.10^{* * *} \\
(0.01)\end{array}$ & $\begin{array}{c}-0.06^{* * *} \\
(0.01)\end{array}$ & $\begin{array}{c}0.02 \\
(0.04)\end{array}$ & $\begin{array}{l}0.08^{*} \\
(0.04)\end{array}$ \\
\hline social & & $\begin{array}{l}0.01^{*} \\
(0.01)\end{array}$ & $\begin{array}{c}0.02^{* * *} \\
(0.01)\end{array}$ & $\begin{array}{c}0.01 \\
(0.01)\end{array}$ & $\begin{array}{c}0.03^{* * *} \\
(0.01)\end{array}$ \\
\hline ps & & $\begin{array}{c}0.01^{* *} \\
(0.00)\end{array}$ & $\begin{array}{l}-0.00 \\
(0.00)\end{array}$ & $\begin{array}{c}0.01^{* *} \\
(0.01)\end{array}$ & $\begin{array}{l}-0.00 \\
(0.01)\end{array}$ \\
\hline literacy & & $\begin{array}{c}0.04^{* * *} \\
(0.01)\end{array}$ & $\begin{array}{c}0.01 \\
(0.01)\end{array}$ & $\begin{array}{c}0.04^{* * *} \\
(0.01)\end{array}$ & $\begin{array}{l}-0.01 \\
(0.01)\end{array}$ \\
\hline numeracy & & $\begin{array}{c}0.00 \\
(0.00)\end{array}$ & $\begin{array}{l}-0.00 \\
(0.00)\end{array}$ & $\begin{array}{c}0.01 \\
(0.01)\end{array}$ & $\begin{array}{c}0.00 \\
(0.01)\end{array}$ \\
\hline $\mathrm{ICT}$ & & $\begin{array}{c}0.07^{* * *} \\
(0.01)\end{array}$ & $\begin{array}{c}0.05^{* * *} \\
(0.01)\end{array}$ & $\begin{array}{c}0.07^{* * *} \\
(0.01)\end{array}$ & $\begin{array}{c}0.07^{* * *} \\
(0.01)\end{array}$ \\
\hline organisation & & $\begin{array}{c}0.01^{* * *} \\
(0.00)\end{array}$ & $\begin{array}{c}0.01 \\
(0.00)\end{array}$ & $\begin{array}{c}0.01^{* *} \\
(0.01)\end{array}$ & $\begin{array}{c}0.01 \\
(0.01)\end{array}$ \\
\hline manual & & $\begin{array}{c}-0.04^{* * *} \\
(0.00)\end{array}$ & $\begin{array}{c}-0.03^{* * *} \\
(0.00)\end{array}$ & $\begin{array}{c}-0.04^{* * *} \\
(0.00)\end{array}$ & $\begin{array}{c}-0.04^{* * *} \\
(0.00)\end{array}$ \\
\hline female*social & & & & $\begin{array}{l}-0.00 \\
(0.01)\end{array}$ & $\begin{array}{r}-0.02^{*} \\
(0.01)\end{array}$ \\
\hline female*problem & & & & & \\
\hline${ }_{s}$ olving & & & & $\begin{array}{l}-0.01 \\
(0.01)\end{array}$ & $\begin{array}{l}-0.00 \\
(0.01)\end{array}$ \\
\hline female*literacy & & & & $\begin{array}{c}0.00 \\
(0.01)\end{array}$ & $\begin{array}{c}0.01 \\
(0.02)\end{array}$ \\
\hline female*numeracy & & & & $\begin{array}{l}-0.02^{*} \\
(0.01)\end{array}$ & $\begin{array}{c}-0.02^{* *} \\
(0.01)\end{array}$ \\
\hline female*ICT & & & & $\begin{array}{l}-0.01 \\
(0.01)\end{array}$ & $\begin{array}{l}-0.02 \\
(0.01)\end{array}$ \\
\hline female*organisation & & & & $\begin{array}{l}-0.01 \\
(0.01)\end{array}$ & $\begin{array}{l}-0.01 \\
(0.01)\end{array}$ \\
\hline female*manual & & & & $\begin{array}{c}0.00 \\
(0.01) \\
\end{array}$ & $\begin{array}{c}0.01 \\
(0.01) \\
\end{array}$ \\
\hline Human Capital & $\checkmark$ & $\checkmark$ & $\checkmark$ & $\checkmark$ & $\checkmark$ \\
\hline Country dummies & $\checkmark$ & $\checkmark$ & $\checkmark$ & $\checkmark$ & $\checkmark$ \\
\hline Occupation dummies & - & - & $\checkmark$ & - & $\checkmark$ \\
\hline$N$ & 18728 & 14940 & 14906 & 14940 & 14906 \\
\hline$R^{2}$ & 0.325 & 0.332 & 0.405 & 0.332 & 0.383 \\
\hline
\end{tabular}

The dependent variable is the ppp-corrected log of hourly wages. Human Capital Controls include education dummies: less than high school, high school (reference), tertiary education; experience and experience squared; whether the individual is native speaker. Country dummies include Belgium, Denmark, The Netherlands, Norway, the UK. 4-digit occupation controls are included. All employed individuals 16-64, excluding self-employed. ${ }^{*} p<0.10,{ }^{* *} p<0.05,{ }^{* * *} p<0.01$ 
Table 12: OLS Regressions of Log Hourly wage on Tasks and Gender - Southern Europe

\begin{tabular}{|c|c|c|c|c|c|}
\hline & (1) & $(2)$ & $(3)$ & (4) & $(5)$ \\
\hline female & $\begin{array}{c}-0.11^{* * *} \\
(0.01)\end{array}$ & $\begin{array}{c}-0.11^{* * *} \\
(0.01)\end{array}$ & $\begin{array}{c}-0.06^{* * *} \\
(0.01)\end{array}$ & $\begin{array}{c}-0.21^{* * *} \\
(0.06)\end{array}$ & $\begin{array}{l}-0.06 \\
(0.07)\end{array}$ \\
\hline social & & $\begin{array}{c}0.04^{* * *} \\
(0.01)\end{array}$ & $\begin{array}{l}0.01^{*} \\
(0.01)\end{array}$ & $\begin{array}{c}0.03^{* * *} \\
(0.01)\end{array}$ & $\begin{array}{c}0.01 \\
(0.01)\end{array}$ \\
\hline ps & & $\begin{array}{l}-0.00 \\
(0.01)\end{array}$ & $\begin{array}{l}-0.01 \\
(0.01)\end{array}$ & $\begin{array}{l}-0.01 \\
(0.01)\end{array}$ & $\begin{array}{l}-0.01 \\
(0.01)\end{array}$ \\
\hline literacy & & $\begin{array}{c}0.07 * * * \\
(0.01)\end{array}$ & $\begin{array}{c}0.03^{* * *} \\
(0.01)\end{array}$ & $\begin{array}{c}0.05^{* * *} \\
(0.01)\end{array}$ & $\begin{array}{c}0.04^{* *} \\
(0.02)\end{array}$ \\
\hline numeracy & & $\begin{array}{c}-0.03^{* * *} \\
(0.01)\end{array}$ & $\begin{array}{c}-0.02^{* *} \\
(0.01)\end{array}$ & $\begin{array}{c}-0.02^{* *} \\
(0.01)\end{array}$ & $\begin{array}{c}-0.02^{* *} \\
(0.01)\end{array}$ \\
\hline $\mathrm{ICT}$ & & $\begin{array}{c}0.01 \\
(0.01)\end{array}$ & $\begin{array}{l}0.02^{* *} \\
(0.01)\end{array}$ & $\begin{array}{l}0.02^{*} \\
(0.01)\end{array}$ & $\begin{array}{c}0.03^{* *} \\
(0.01)\end{array}$ \\
\hline organisation & & $\begin{array}{c}0.03^{* * *} \\
(0.01)\end{array}$ & $\begin{array}{c}0.02^{* * *} \\
(0.01)\end{array}$ & $\begin{array}{c}0.04^{* * *} \\
(0.01)\end{array}$ & $\begin{array}{c}0.04^{* * *} \\
(0.01)\end{array}$ \\
\hline manual & & $\begin{array}{c}-0.04^{* * *} \\
(0.00)\end{array}$ & $\begin{array}{c}-0.03^{* * *} \\
(0.00)\end{array}$ & $\begin{array}{c}-0.05^{* * *} \\
(0.01)\end{array}$ & $\begin{array}{c}-0.04^{* * *} \\
(0.01)\end{array}$ \\
\hline female*social & & & & $\begin{array}{c}0.00 \\
(0.02)\end{array}$ & $\begin{array}{l}-0.02 \\
(0.02)\end{array}$ \\
\hline female*problem & & & & & \\
\hline${ }_{\text {solving }}$ & & & & $\begin{array}{l}0.02 * \\
(0.01)\end{array}$ & $\begin{array}{l}0.02^{*} \\
(0.01)\end{array}$ \\
\hline female*literacy & & & & $\begin{array}{c}0.02 \\
(0.02)\end{array}$ & $\begin{array}{l}-0.01 \\
(0.02)\end{array}$ \\
\hline female*numeracy & & & & $\begin{array}{l}-0.01 \\
(0.01)\end{array}$ & $\begin{array}{l}-0.00 \\
(0.01)\end{array}$ \\
\hline female*ICT & & & & $\begin{array}{l}-0.01 \\
(0.02)\end{array}$ & $\begin{array}{l}-0.01 \\
(0.02)\end{array}$ \\
\hline female*organisation & & & & $\begin{array}{l}-0.01 \\
(0.01)\end{array}$ & $\begin{array}{l}-0.01 \\
(0.01)\end{array}$ \\
\hline female*manual & & & & $\begin{array}{c}0.02^{* *} \\
(0.01)\end{array}$ & $\begin{array}{c}0.01 \\
(0.01)\end{array}$ \\
\hline$N$ & 9488 & 5876 & 5873 & 5876 & 5873 \\
\hline$R^{2}$ & 0.320 & 0.342 & 0.459 & 0.344 & 0.410 \\
\hline Human Capital & $\checkmark$ & $\checkmark$ & $\checkmark$ & $\checkmark$ & $\checkmark$ \\
\hline Country dummies & $\checkmark$ & $\checkmark$ & $\checkmark$ & $\checkmark$ & $\checkmark$ \\
\hline Occupation dummies & - & - & $\checkmark$ & - & $\checkmark$ \\
\hline
\end{tabular}

The dependent variable is the ppp-corrected log of hourly wages. Human Capital Controls include education dummies: less than high school, high school (reference), tertiary education; experience and experience squared; whether the individual is native speaker. Country dummies include France, Italy, Greece, Spain.4-digit occupation controls are included where indicated. All employed individuals 16-64, excluding self-employed. * $p<0.10,{ }^{* *} p<0.05,{ }^{* * *} p<0.01$ 
Table 13: OLS Regressions of Log Hourly wage on Tasks and Gender - Eastern Europe

\begin{tabular}{|c|c|c|c|c|c|}
\hline & (1) & $(2)$ & $(3)$ & (4) & $(5)$ \\
\hline female & $\begin{array}{c}-0.21^{* * *} \\
(0.01)\end{array}$ & $\begin{array}{c}-0.19^{* * *} \\
(0.01)\end{array}$ & $\begin{array}{c}-0.13^{* * *} \\
(0.02)\end{array}$ & $\begin{array}{l}-0.14^{*} \\
(0.08)\end{array}$ & $\begin{array}{l}-0.04 \\
(0.08)\end{array}$ \\
\hline social & & $\begin{array}{l}-0.01 \\
(0.01)\end{array}$ & $\begin{array}{l}-0.01 \\
(0.01)\end{array}$ & $\begin{array}{c}0.00 \\
(0.01)\end{array}$ & $\begin{array}{c}0.02 \\
(0.02)\end{array}$ \\
\hline ps & & $\begin{array}{c}0.02^{* * *} \\
(0.01)\end{array}$ & $\begin{array}{c}0.01 \\
(0.01)\end{array}$ & $\begin{array}{c}0.04^{* * *} \\
(0.01)\end{array}$ & $\begin{array}{l}0.02^{*} \\
(0.01)\end{array}$ \\
\hline literacy & & $\begin{array}{c}0.04^{* * *} \\
(0.01)\end{array}$ & $\begin{array}{c}0.03^{* *} \\
(0.01)\end{array}$ & $\begin{array}{c}0.02 \\
(0.02)\end{array}$ & $\begin{array}{c}0.02 \\
(0.02)\end{array}$ \\
\hline numeracy & & $\begin{array}{l}-0.01 \\
(0.01)\end{array}$ & $\begin{array}{l}-0.01 \\
(0.01)\end{array}$ & $\begin{array}{c}0.01 \\
(0.01)\end{array}$ & $\begin{array}{c}0.01 \\
(0.01)\end{array}$ \\
\hline $\mathrm{ICT}$ & & $\begin{array}{c}0.05^{* * *} \\
(0.01)\end{array}$ & $\begin{array}{c}0.04^{* * *} \\
(0.01)\end{array}$ & $\begin{array}{l}0.02^{*} \\
(0.01)\end{array}$ & $\begin{array}{c}0.01 \\
(0.02)\end{array}$ \\
\hline organisation & & $\begin{array}{c}0.04^{* * *} \\
(0.01)\end{array}$ & $\begin{array}{c}0.03^{* * *} \\
(0.01)\end{array}$ & $\begin{array}{c}0.04^{* * *} \\
(0.01)\end{array}$ & $\begin{array}{c}0.03^{* * *} \\
(0.01)\end{array}$ \\
\hline manual & & $\begin{array}{c}-0.05^{* * *} \\
(0.01)\end{array}$ & $\begin{array}{c}-0.05^{* * *} \\
(0.01)\end{array}$ & $\begin{array}{c}-0.06^{* * *} \\
(0.01)\end{array}$ & $\begin{array}{c}-0.06^{* * *} \\
(0.01)\end{array}$ \\
\hline female*social & & & & $\begin{array}{l}-0.03 \\
(0.02)\end{array}$ & $\begin{array}{c}-0.04^{* *} \\
(0.02)\end{array}$ \\
\hline female*problem & & & & & \\
\hline${ }_{s}$ olving & & & & $\begin{array}{c}-0.03^{* *} \\
(0.01)\end{array}$ & $\begin{array}{c}-0.03^{*} \\
(0.01)\end{array}$ \\
\hline female*literacy & & & & $\begin{array}{c}0.03 \\
(0.03)\end{array}$ & $\begin{array}{c}0.01 \\
(0.03)\end{array}$ \\
\hline female*numeracy & & & & $\begin{array}{c}-0.04^{* *} \\
(0.02)\end{array}$ & $\begin{array}{c}-0.03^{* *} \\
(0.02)\end{array}$ \\
\hline female*ICT & & & & $\begin{array}{c}0.05^{* *} \\
(0.02)\end{array}$ & $\begin{array}{c}0.07^{* * *} \\
(0.02)\end{array}$ \\
\hline female*organisation & & & & $\begin{array}{l}-0.01 \\
(0.01)\end{array}$ & $\begin{array}{l}-0.02 \\
(0.01)\end{array}$ \\
\hline female*manual & & & & $\begin{array}{c}0.01 \\
(0.01)\end{array}$ & $\begin{array}{l}0.02^{*} \\
(0.01)\end{array}$ \\
\hline Human Capital & $\checkmark$ & $\checkmark$ & $\checkmark$ & $\checkmark$ & $\checkmark$ \\
\hline Country dummies & $\checkmark$ & $\checkmark$ & $\checkmark$ & $\checkmark$ & $\checkmark$ \\
\hline Occupation dummies & - & - & $\checkmark$ & - & $\checkmark$ \\
\hline$N$ & 11387 & 6798 & 6798 & 6798 & 6798 \\
\hline$R^{2}$ & 0.167 & 0.212 & 0.305 & 0.215 & 0.307 \\
\hline
\end{tabular}

The dependent variable is the ppp-corrected log of hourly wages. Human Capital Controls include education dummies: less than high school, high school (reference), tertiary education; experience and experience squared; whether the individual is native speaker. Country dummies include Czechia, Poland, Slovakia, Slovenia. 4-digit occupation controls are included where indicated. All employed individuals 16-64, excluding self-employed. ${ }^{*} p<0.10,{ }^{* *} p<0.05,{ }^{* * *} p<0.01$ 


\section{Appendix}

Table A.1: Tasks in the PIAAC data

\begin{tabular}{|c|c|}
\hline $\begin{array}{l}\text { Social tasks } \\
\text { sharing work-related info } \\
\text { teaching people } \\
\text { presentations } \\
\text { selling } \\
\text { advising people } \\
\text { influencing people } \\
\text { negotiating with people } \\
\text { cooperating with others } \\
\text { Problem solving } \\
\text { simple problems } \\
\text { complex problems } \\
\text { Literacy tasks } \\
\text { Reading } \\
\text { read directions or instructions } \\
\text { read letters, memos or mails } \\
\text { read newspapers or magazines } \\
\text { read professional journals or publications } \\
\text { read books } \\
\text { read manuals or reference materials } \\
\text { read financial statements } \\
\text { read diagrams, maps or schematics } \\
W r i t i n g \\
\text { write letters, memos or mails } \\
\text { write articles } \\
\text { write reports } \\
\text { fill in forms }\end{array}$ & $\begin{array}{l}\text { Numeracy tasks } \\
\text { calculating costs or budgets } \\
\text { use or calculate fractions or percentages } \\
\text { use a calculator } \\
\text { prepare graphs, charts or tables } \\
\text { use simple algebra or formulas } \\
\text { use advanced math or statistics } \\
\text { ICT tasks } \\
\text { use Internet for mail } \\
\text { use Internet to find work-related info } \\
\text { use Internet to conduct transactions } \\
\text { use computer to work with spreadsheets } \\
\text { use computer to work with Word } \\
\text { use computer for programming } \\
\text { use computer for conference calls } \\
\text { Management tasks } \\
\text { planning own activities } \\
\text { planning others' activities } \\
\text { organising own time } \\
\text { Manual tasks } \\
\text { working physically for long } \\
\text { using hands or fingers }\end{array}$ \\
\hline
\end{tabular}


Table A.2: Skill Use at Work by Gender

\begin{tabular}{|c|c|c|c|c|c|c|c|c|c|c|c|c|c|}
\hline & BEL & CZE & DNK & FRA & GRC & ITA & NLD & NOR & POL & SVK & SVN & ESP & UK \\
\hline \multicolumn{14}{|l|}{ Social } \\
\hline Male & 2.8 & 2.7 & 3.0 & 2.7 & 2.6 & 2.6 & 2.8 & 3.0 & 2.6 & 2.6 & 2.8 & 2.7 & 3.0 \\
\hline Female & 2.6 & 2.7 & 3.0 & 2.6 & 2.6 & 2.5 & 2.6 & 2.9 & 2.7 & 2.6 & 2.9 & 2.5 & 3.1 \\
\hline \multicolumn{14}{|c|}{ Management } \\
\hline Male & 3.5 & 3.8 & 3.8 & 3.4 & 3.3 & 3.6 & 3.6 & 3.7 & 3.5 & 3.2 & 3.1 & 3.5 & 3.6 \\
\hline Female & 3.5 & 3.6 & 3.6 & 3.3 & 3.1 & 3.5 & 3.5 & 3.5 & 3.5 & 3.1 & 3.1 & 3.4 & 3.7 \\
\hline \multicolumn{14}{|c|}{ Problem Solving } \\
\hline Male & 3.4 & 3.6 & 3.5 & 3.4 & 3.4 & 3.6 & 3.4 & 3.6 & 3.1 & 3.6 & 3.3 & 3.4 & 3.6 \\
\hline Female & 3.2 & 3.2 & 3.4 & 3.1 & 3.2 & 3.4 & 3.1 & 3.3 & 3.0 & 3.3 & 3.2 & 3.1 & 3.5 \\
\hline \multicolumn{14}{|c|}{ Literacy } \\
\hline Male & 2.7 & 2.6 & 2.8 & 2.6 & 2.2 & 2.4 & 2.8 & 3.0 & 2.3 & 2.4 & 2.6 & 2.5 & 2.9 \\
\hline Female & 2.6 & 2.5 & 2.7 & 2.4 & 2.2 & 2.3 & 2.7 & 2.8 & 2.4 & 2.4 & 2.7 & 2.3 & 2.8 \\
\hline \multicolumn{14}{|c|}{ Numeracy } \\
\hline Male & 2.3 & 2.7 & 2.5 & 2.3 & 2.3 & 2.2 & 2.4 & 2.5 & 2.2 & 2.4 & 2.4 & 2.3 & 2.4 \\
\hline Female & 2.0 & 2.5 & 2.0 & 2.1 & 2.2 & 2.0 & 1.9 & 2.0 & 2.3 & 2.4 & 2.4 & 2.1 & 2.2 \\
\hline \multicolumn{14}{|l|}{$I C T$} \\
\hline Male & 2.9 & 2.9 & 3.0 & 2.7 & 2.7 & 2.9 & 3.0 & 3.0 & 2.7 & 2.9 & 2.9 & 2.8 & 2.9 \\
\hline Female & 2.8 & 2.8 & 2.8 & 2.7 & 2.6 & 2.8 & 2.7 & 2.6 & 2.7 & 2.9 & 2.9 & 2.7 & 2.8 \\
\hline \multicolumn{14}{|l|}{ Manual } \\
\hline Male & 3.3 & 3.4 & 3.5 & 3.3 & 3.6 & 3.5 & 3.2 & 3.1 & 4.1 & 3.8 & 4.0 & 3.5 & 3.6 \\
\hline Female & 3.2 & 3.4 & 3.6 & 2.8 & 3.3 & 3.1 & 3.2 & 3.1 & 3.5 & 3.5 & 3.8 & 3.1 & 3.5 \\
\hline
\end{tabular}

The sample includes employed individuals only (no self-employed). Skill use is self-reported. The scale of skill use goes from 1 to 5 , where 1 is 'never' and 5 is 'every day'. Raw averages only. 


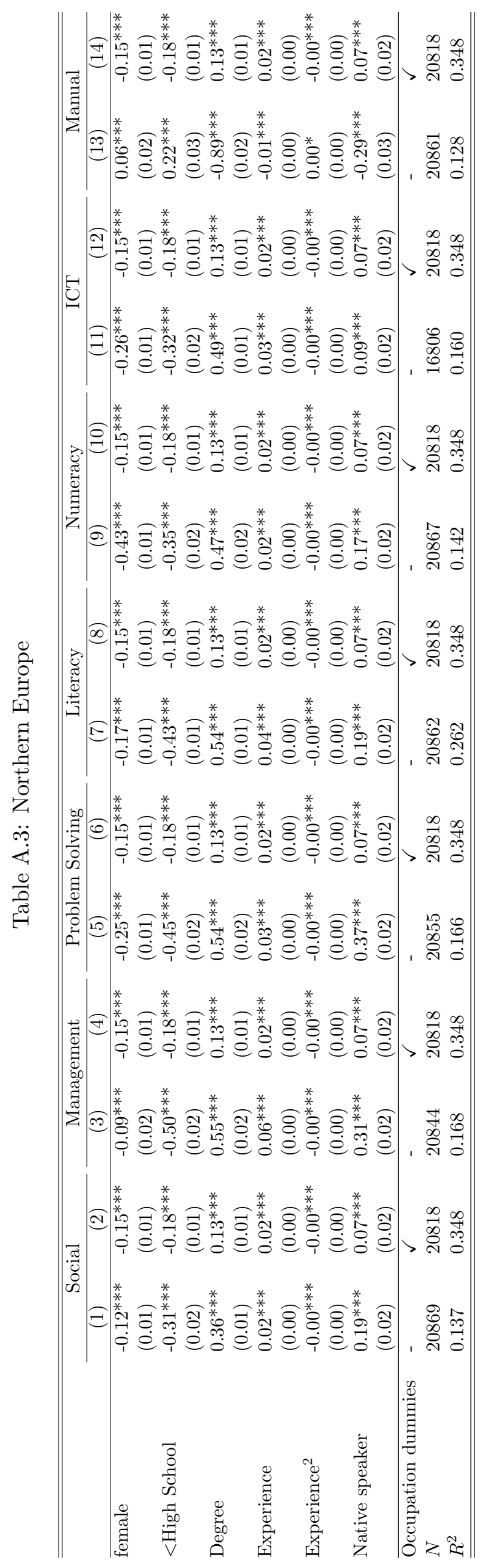




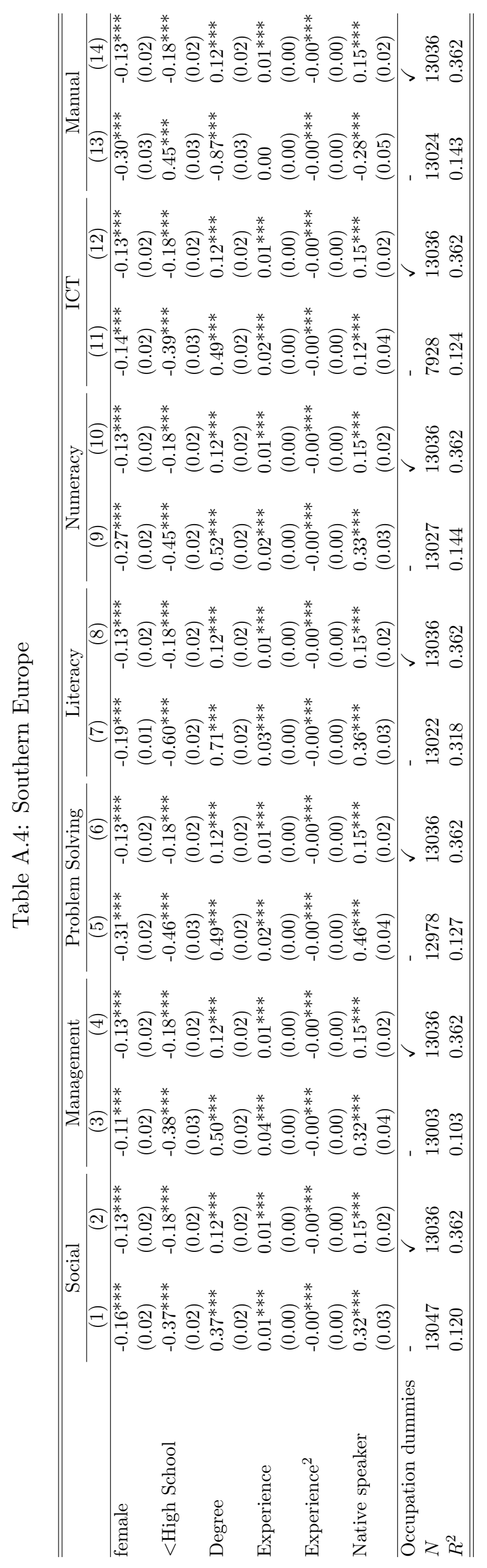




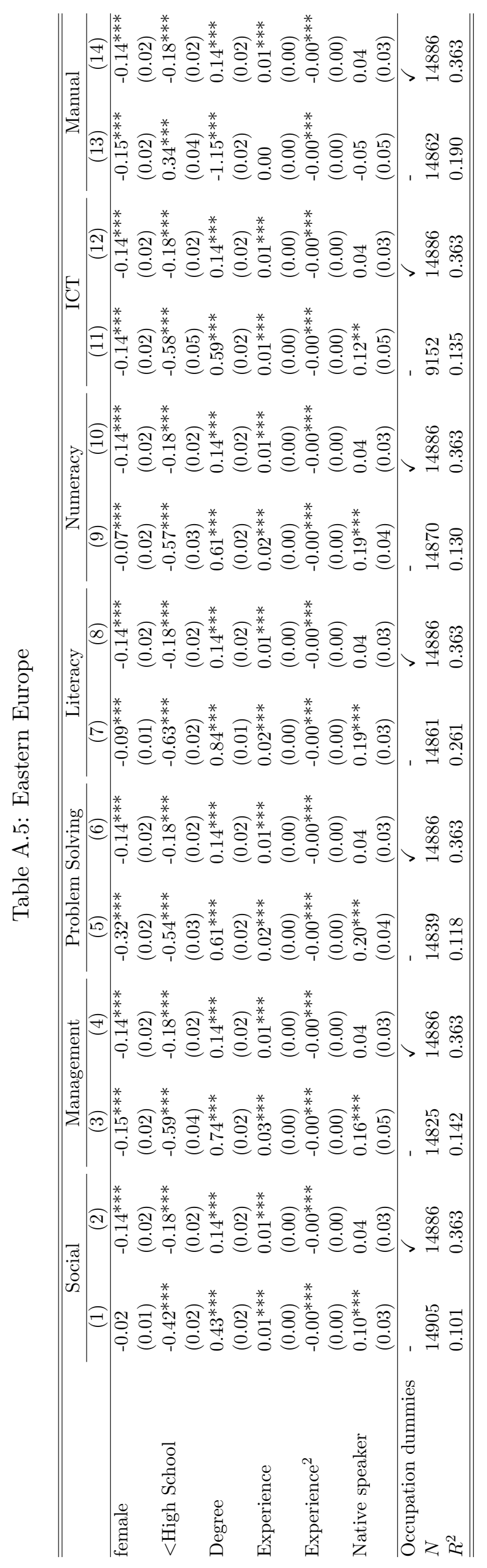

